NBER WORKING PAPER SERIES

\title{
RUNOFF ELECTIONS IN THE LABORATORY
}

\author{
Laurent Bouton \\ Jorge Gallego \\ Aniol Llorente-Saguer \\ Rebecca Morton \\ Working Paper 25949 \\ http://www.nber.org/papers/w25949 \\ NATIONAL BUREAU OF ECONOMIC RESEARCH \\ 1050 Massachusetts Avenue \\ Cambridge, MA 02138 \\ June 2019
}

We thank participants of the PEPS Chile 2017, Theem 2018, ESA 2018 and seminar participants at Carlos III, CERGE-EI, Nanyang Technological University, National University of Singapore, Universidad del Rosario, University of Cyprus, University of Edinburgh, University of Padua and Paris School of Economics. We extend particular thanks to Micael Castanheira Jon Woon for insightful comments. We would also like to thank Mateo Vasquez and Taylor Mattia for their excellent assistance with running the experiments. This project has received funding from the European Research Council (Laurent Bouton) under the European Union's Horizon 2020 research and innovation programme (grant agreement No 637662). The views expressed herein are those of the authors and do not necessarily reflect the views of the National Bureau of Economic Research.

NBER working papers are circulated for discussion and comment purposes. They have not been peer-reviewed or been subject to the review by the NBER Board of Directors that accompanies official NBER publications.

(C) 2019 by Laurent Bouton, Jorge Gallego, Aniol Llorente-Saguer, and Rebecca Morton. All rights reserved. Short sections of text, not to exceed two paragraphs, may be quoted without explicit permission provided that full credit, including $(\subseteq)$ notice, is given to the source. 
Runoff Elections in the Laboratory

Laurent Bouton, Jorge Gallego, Aniol Llorente-Saguer, and Rebecca Morton

NBER Working Paper No. 25949

June 2019

JEL No. C92,D7

\begin{abstract}
We study experimentally the properties of the majority runoff system and compare them to the ones of plurality rule, in the setup of a divided majority. Our focus is on Duverger's famous predictions that the plurality rule leads to a higher coordination of votes on a limited number of candidates than the majority runoff rule. Our experiments show that, in contradiction with Duverger's predictions, coordination forces are strong in majority runoff elections. We indeed observe similar levels of coordination under both rules, even when sincere voting is an equilibrium only under majority runoff. Our results suggest that the apparent desire to coordinate, and not vote sincerely, under the majority runoff rule is to some extent not rational. Finally, we find insignificant differences between runoff and plurality systems in terms of both electoral outcomes and welfare. This is so exactly because coordination forces are strong under both rules. But, this does not mean that the two rules are equally socially desirable. Majority runoff rule entails an additional cost: second rounds that take place frequently.

Laurent Bouton

Georgetown University

Department of Economics

37th \& O Streets, NW

Washington,DC 20057

and CEPR

and also NBER

boutonllj@gmail.com

Jorge Gallego

Universidad del Rosario

Department of Economics

Aniol Llorente-Saguer

School of Economics and Finance

Queen Mary, University of London

Mile End Road, London E1 4NS

United Kingdom

a.llorente-saguer@qmul.ac.uk

Rebecca Morton

New York University

19 West 4th St. 2nd Floor

New York, NY 10012

rebecca.morton@nyu.edu
\end{abstract}

jagallegod@gmail.com 


\section{Introduction}

With the spread of democracy worldwide since the end of World War II, there has been an increase in the use of majority requirements in which a candidate cannot secure election unless he or she has received a majority of the votes (see Figure 1). When no candidate receives a majority, then the requirements result in a second round between the top two vote receivers to determine which candidate wins. This electoral rule is refered to as the $m a$ jority runoff rule. In contrast, in a plurality rule or first-past-the-post election, whichever candidate receives the most votes is declared the winner. Majority runoff elections are not new: they appear to have existed as long as plurality rule elections in western countries, and were reportedly used in the Ancient regime in France. ${ }^{1}$ They have traditionally been used for French presidential elections, legislative elections in Australia, and in many mayoral, legislative, and state-wide contests in the United States. ${ }^{2}$ More recently, it has been adopted during the democratic transition in Eastern Europe, Africa, and to a lesser extent Latin America. Majority runoff rules are also often used when committees or legislatures are selecting leaders and there are more than two candidates. ${ }^{3}$

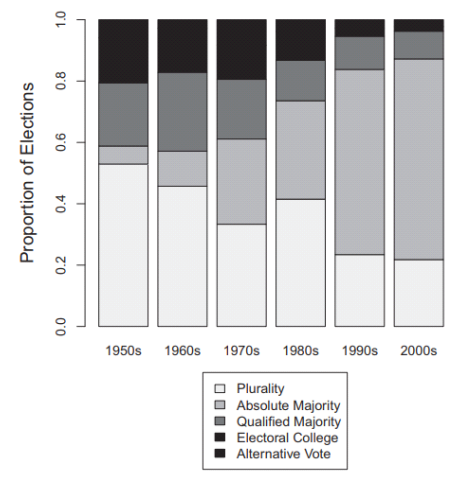

Figure 1: Electoral systems used in the world. Majority runoff elections are reported under "Absolute Majority". Source: Bormann and Golder (2013, Figure 7)

Nevertheless, many elections continue to be conducted under plurality rule. The most

\footnotetext{
${ }^{1}$ See Colomer (2007) for a history of use of majority requirements from the French Revolution; he records their use at various points in the 1800s by Belgium, France, Greece, Honduras, the Netherlands, Spain, and Switzerland.

${ }^{2}$ The electoral college system used to select US presidents has a majority requirement as well, although the second stage of the system is decided by a different set of voters than in the first stage.

${ }^{3}$ For example, in 2016 three members of the Louisiana House of Representatives vied to be Louisiana House Speaker and a second round was held between the two top candidates when none received a majority in the first round of voting. See Ballard (2016).
} 
obvious reason for not adopting majority requirements ${ }^{4}$ are the costs involved in a twostage election process which increases (i) expenses paid by government agencies to conduct elections (doubling the variable expenses) ${ }^{5}$ (ii) voting costs since voters have to go to the polls twice, ${ }^{6}$ and (iii) campaign costs because of the longer election process. ${ }^{7}$ Clearly some have concluded that any advantages from runoff rules are not worth these costs.

But, what are the advantages? In this paper we focus on one in particular: ${ }^{8}$ the perception that in majority runoff elections, voters in the first round can express their preferences more "sincerely", i.e., vote for their favorite candidate, than in a plurality rule contest and thus voters' preferences can be more accurately observed and understood. That is, in a plurality election, if a voter believes that her favorite candidate does not have enough support to defeat the other candidates, she will find it desirable to abandon her favorite candidate and instead vote strategically for a less-preferred one. This reasoning leads to a concentration of votes on two candidates-the so-called Duverger's Law (Duverger 1959, Riker 1982, Palfrey 1989). In a runoff system, voters are arguably less concerned about whether their favorite candidate can defeat the rest of the field in the first stage, but whether the candidate can at least make it to the second round. Thus voters are believed to be more likely to vote sincerely for their favorite candidate in the first round-the so-called Duverger's Hypothesis (Duverger 1959, Riker 1982, Martinelli 2002). ${ }^{9}$

As we discuss in the next section, the recent theoretical literature has cast doubt on the extent that voters vote (more) sincerely in the first round of a majority runoff election,

\footnotetext{
${ }^{4}$ Other drawbacks associated with the use of runoff rules include party fragmentation (Shugart and Carey 1994), the existence of a potential harmful strategic behavior by voters in the first round called "push-over" (Smith 1973, Cox 1997, Saari 2003), and an increase in the risk that the median candidate is "squeezed" out of the second round (Solow 2019, and Van Der Straeten et al. 2012).

${ }^{5}$ In the 2013 NYC election for Public Advocate the 2 nd round cost $\$ 13$ million to conduct, although the office has an annual budget of only $\$ 2.3$ million. Therefore the government spent more conducting the $2 \mathrm{nd}$ round than the candidates will have control over during their 4 years in office (https://nyti.ms/2VDya1h).

${ }^{6}$ These costs are far from trivial: Stewart and Ansolabehere (2015, page 48) report that long lines at ballot places alone had "an estimated economic cost of $\$ 544.4$ million in election line-waiting in 2012 , which is about one-fifth the budget of local election offices in 2012 [...]"

${ }^{7}$ An extreme case of potential negative consequences is mentioned by Perez-Linan (2006, p. 136): "[...] additional financial needs created by the Colombian runoff campaign in 1994 led Ernesto Samper's operatives to accept contributions from the Cali drug cartel (Medina Serna, 1997)."

${ }^{8}$ Some of the advantages not addressed in this paper include: (i) Candidates elected through majority runoff elections are assured of having received at least majority support in the election and thus can contend that they have a mandate of democratic legitimacy (see the discussions in Perez-Linan 2006 and McClintock 2018); (ii) Candidates have incentives to cater to the interests of a broad coalition of voters (see, e.g., Lizzeri and Persico 2005); (iii) Voters can more easily transmit information about their policy preferences to candidates (Piketty 2000, Castanheira 2003, Blais 2004a,b).

${ }^{9}$ See Riker (1982) for a discussion of the history of thought concerning these two relationships. See also our review of the literature in the next section.
} 
demonstrating that the forces toward coordination are also present in those elections (see Bouton 2013, Bouton and Graton 2015, and Bouton and Ogden 2017). These forces can be so strong as to prevent the existence of an equilibrium in which voters vote sincerely. These new theoretical results provide a possible explanation for the mixed observational empirical evidence about the different strengths of Duvergerian forces in plurality versus runoff systems (which we also review in the next section). However, these observational studies provide only indirect evidence of the effects of majority requirements on voter behavior.

In this paper, we investigate the effects of majority requirements on preference revelation using laboratory experiments. We find that, under the majority runoff rule, there are strong coordination forces which lead to insincere voting. In fact, the voting behavior under the majority runoff rule is similar to that observed under plurality rule. Under both systems, we find little support for the sincere voting equilibrium. Furthermore, our results suggest that the apparent desire to coordinate, and not vote sincerely, is to some extent not rational. It appears to reflect an excessive and irrational focus on the first round. Our results imply that in terms of voting behavior there are few institutional differences between plurality and majority runoff elections. In the laboratory, majority runoff elections are not more conducive to preference revelation than plurality elections.

However, similar voting behavior does not necessarily mean similar electoral outcomes. Runoff and plurality systems can map votes into outcomes differently. While theoretically possible, this difference does not appear in our laboratory experiments. We find insignificant differences between runoff and plurality systems in terms of both electoral outcomes and welfare. This lack of difference occurs because voters coordinate behind two alternatives under both types of elections. But, that does not mean that the two rules are equally socially desirable. One important difference our experiments highlight is that the runoff rule entails an additional cost for society: second rounds, which are costly and take place frequently. And, both in real-life and in our laboratory experiments, many of those second rounds prove "useless": the election's winner corresponds to the first-round winner (e.g., Engstrom and Engstrom 2008 find that, in US primaries, this occurs approximately $70 \%$ of the times).

Our experimental approach is particularly well-suited to explore the causal impact of 
an electoral system on voting behavior. It indeed does not face a number of important challenges that observational studies have to overcome to produce reliable estimates. First, as Acemoglu (2005) notes, institutions are endogenous themselves. For instance, the majority runoff rule may be more likely to be adopted where and when voters have a tendency to vote sincerely. Second, electoral systems affect not only voters' behavior but also candidates and parties behavior, which makes it difficult to determine if observed differences are due to voter behavioral responses or candidate choices (see, e.g., Palfrey 1984, Osborne and Slivinski, and Callander 2005 for analyses of candidate entry behavior under plurality and majority runoff rules). Third, when comparing electoral systems one must, most of the time, control for many important differences between countries in other dimensions such as culture and institutions that can profoundly affect electoral choices and voters behavior. ${ }^{10}$ The obvious drawback of our approach is the potential lack of external validity. We thus see the different approaches as complementary.

\section{Review of the Literature}

The idea that runoff elections lead to sincere voting and the viability of more than two electoral choices (either candidates or parties) was expressed as far back as the mid nineteenth century. Riker (1982) traces the first statement that plurality rule leads to two parties and strategic voting to Henry Droop, writing in 1869. Nevertheless, it is usually associated with Duverger (1959). As Riker (1982) notes, the first effect, that plurality rule leads to a domination of the top two choices is known as Duverger's Law. The second effect, that runoff systems lead to more sincere voting and thus more than two viable choices, was considered more of a hypothesis than a law by Duverger, hence Riker labels it as Duverger's Hypothesis. Duverger argued that there were two sources for the effects, one source is a "mechanical effect" of parties not entering or forming coalitions of larger parties in anticipation of the difficulty of achieving enough votes to win. The other is a "psychological effect", that in a first-past-the-post election, voters abandon their first choice if it is unlikely to contend for victory, and instead vote strategically for their favorite contender. Duverger's Hypothesis, likewise rests on the argument that in majority

\footnotetext{
${ }^{10}$ This last challenge is not relevant for recent within country studies that rely on RDD (see, e.g., Fujiwara 2011, Bordignon et al. 2015).
} 
runoff elections, in the first round, both effects are less present, with more, smaller parties entering competition and voters not so attracted to abandon favorite choices when they are trailing behind. Our focus in this paper is on Duverger's Hypothesis and the extent that the psychological effect is less prevalent from the first round of voting in a majority runoff election than in a plurality election. Hence, we consider voter behavior holding candidate and party behavior fixed. ${ }^{11}$

The more recent, game-theoretic, literature refines Duverger's predictions and our understanding of voters' behavior under plurality and majority runoff. ${ }^{12}$ In plurality elections, there are always multiple Duverger's Law equilibria, in which only two candidates receive votes, and the sincere voting equilibrium does not exist generically (see, e.g, Palfrey 1989, Myerson and Weber 1993, and Cox 1997). ${ }^{13}$ By contrast, in the first round of majority runoff elections, the sincere voting equilibrium, or an equilibrium in which more than two candidates receive a positive share of the votes, exists for a broad range of situations, but Duverger's law equilibria exist only if, in the first round, there is sufficient uncertainty about the outcome of the second round (Bouton 2013, Bouton and Gratton 2015, and Bouton and Ogden 2017). Our paper contributes to this literature in two ways. First, we extend some of those theoretical results to a case with a small number of voters. Second, and more importantly, we explore in the laboratory the strength of the coordination forces under plurality and majority runoff.

Empirical evidence on Duverger's Hypothesis is mixed. There are many observational empirical cases where runoff systems exist with less than three viable or effective candidates (see Wright and Riker 1989 and Shugart and Taagepera 1994). Large $n$ empirical analyses using observational data provides no conclusive evidence. For instance, using Brazilian data and a regression discontinuity design, Fujiwara (2011) finds a strong negative effect of the majority runoff on the vote share of the top-two candidates (in line with Duverger's

\footnotetext{
${ }^{11}$ See Osborne and Slivinski (1996) and Callander (2005) for studies that examine the mechanical effect.

${ }^{12}$ See, e.g., Palfrey 1989, Myerson and Weber (1993), Cox (1997), Fey (1997), Piketty (2000), Myatt (2007), Martinelli (2002), Bouton (2013), Bouton and Gratton (2015), and Bouton and Ogden (2017).

${ }^{13}$ This statement requires two important clarifications. First, with aggregate uncertainty, (i) the sincere voting equilibrium exists for a broader set of distributions, and (ii) Duverger's law equilibria exist as long as the amount of aggregate uncertainty is not excessive (see Myatt 2007 and Bouton, Castanheira, and Llorente-Saguer 2017). Second, the literature also show the existence of an equilibrium in mixed strategy in which more than two candidates receive a positive fraction of the votes (Myerson and Weber 1993, Fey 1997, Bouton, Castanheira and Llorente-Saguer 2017). The key condition of existence of that equilibrium is that both majority alternatives are equally strong contender of the minority alternative. Without aggregate uncertainty, this equilibrium is unstable and often deemed unreasonable (see, e.g., Fey 1997).
} 
predictions). He also finds suggestive evidence that this result is driven by the strategic behavior of voters. By contrast, using Italian data and a similar regression discontinuity design, Bordignon et al. (2016) finds no effect of the electoral system on the vote share of the top-two candidates. ${ }^{14}$

As noted in the Introduction, the observational studies suffer from a number of serious handicaps in that party and candidate behavior is endogenous as well as the electoral institutions themselves. There have been a few experimental studies of majority requirements which provide better control over possible confounding factors in observational studies (Morton and Rietz 2007, Van Der Straeten et al. 2010, 2016). However, in these studies, voters have complete information as to the distribution of voter preferences, which is both empirically unrealistic and fails to capture the importance of uncertainty about the outcome in the second round highlighted by the aforementioned theoretical literature.

\section{The Model}

This section presents a modified, simplified, version of the model in Bouton (2013). Some elements are borrowed from Bouton and Gratton (2015). There are two main differences. First, we assume that the size of the electorate is fixed at $n$, instead of being randomly distributed according to a Poisson distribution. The main reason for this modification is that it is not practical to have a random and potentially infinite number of voters in the laboratory. Second, we consider any electorate size, which contrasts with most of the literature's focus on large electorates.

We consider the typical case of a divided majority, ${ }^{15}$ with three alternatives, $\{A, B, C\}$, and three types of voters: $t \in T=\left\{t_{A}, t_{B}, t_{C}\right\}$. The electorate is split in two groups: majority and minority voters. Majority voters have a common view that $C$ is the worst alternative. Yet, they disagree on which alternative is best: types- $t_{A}$ prefer $A$ over $B$ whereas types- $t_{B}$ prefer $B$ over $A$. Minority voters are assumed to prefer $C$ and, for the

\footnotetext{
${ }^{14}$ See also Jones (1999), Golder (2006), and Eggers (2015) for evidence of significant differences in voting behavior under plurality and majority runoff, and Cox (1997), and Engstrom and Engstrom (2008) for nonsignificant ones.

${ }^{15}$ The divided majority setting is tractable but still captures some of the fundamental coordination problems that voters face in multicandidate elections. As a consequence, this setting is common in the literature on strategic voting in multicandidate elections. See, e.g., Myerson and Weber (1993), Cox (1997), Fey (1997), Piketty (2000), Myerson (2002), Dewan and Myatt (2007), Myatt (2007), Bouton and Castanheira (2012), and Bouton (2013).
} 
sake of simplicity, to be indifferent between $A$ and $B$; hence their (weakly) dominant strategy is to vote for $C$.

Formally, the utilities of the different types are:

$$
\begin{aligned}
& U\left(A \mid t_{A}\right)>U\left(B \mid t_{A}\right)>U\left(C \mid t_{A}\right), \\
& U\left(B \mid t_{B}\right)>U\left(A \mid t_{B}\right)>U\left(C \mid t_{B}\right), \text { and } \\
& U\left(C \mid t_{C}\right)>U\left(A \mid t_{C}\right)=U\left(B \mid t_{C}\right),
\end{aligned}
$$

where $U(W \mid t)$ denotes the utility of a type- $t$ voter when $W$ is the winning alternative.

Each voter is assigned a type $t$ by i.i.d. draws. The probability that a voter is assigned type $t$ is $r(t)$, with $\sum_{t \in T} r(t)=1$. These probabilities are common knowledge. In the case of the divided majority, we have:

$$
r\left(t_{A}\right)+r\left(t_{B}\right)>\frac{1}{2}>r\left(t_{C}\right)
$$

Alternative $C$ is thus the (expected) Condorcet loser. ${ }^{16}$ We focus on the case in which alternative $C$ is a serious threat to the victory of a majority alternative when majority voters divide their votes: $r\left(t_{C}\right)>1 / 3$.

By convention, we focus on the case in which the "more abundant" type among majority voters is $t_{A}$ :

$$
r\left(t_{A}\right) \geq r\left(t_{B}\right)
$$

Alternative $A$ is thus the (expected) Condorcet winner.

We consider two electoral systems: $S \in\{P, R\}$, where $P$ refers to plurality and $R$ to majority runoff. Under plurality, the election is as follows. There is one round of voting. Each voter casts a ballot in favor of one of the alternatives. The alternative that obtains the largest number of votes wins. ${ }^{17}$ Under majority runoff, the election works as follows. In the first round, each voter casts a ballot in favor of one of the alternatives. If the alternative who ranks first obtains (strictly) more than $50 \%$ of the votes, it wins outright and there is no second round. Otherwise, a second round with the two alternatives that

\footnotetext{
${ }^{16}$ That is, in pairwise contests with the other two candidates, $C$ is the loser. A Condorcet winner has the optimistic property.

${ }^{17}$ For the sake of notational simplicity, ties are resolved by alphabetical order. Results hold if we assume that ties are resolved by the toss of a fair coin.
} 
received the most votes in the first round (called the top-two alternatives) is held. In this round, each voter casts a ballot in favor of one of the top-two alternatives and the alternative that obtains the most votes wins the election. ${ }^{18}$

From Bouton (2013), we know that what happens in the second round of a majority runoff election influences dramatically the behavior of voters in the first round. In particular, a crucial element is the risk of an upset victory in that round. The way we model the second round is thus a sensitive matter. For the sake of expositional clarity, we follow Bouton and Gratton (2015) and work under the assumption that, at the time of the first round, the probabilities of victory of all possible second rounds are given, positive, and constant. ${ }^{19}$ In particular, we denote by $\operatorname{Pr}(i \mid i j), i, j \in\{A, B, C\}$ the probability that alternative $i$ wins a second round opposing alternatives $i$ and $j .{ }^{20}$ The focus under majority runoff is thus on the behavior of voters in the first round.

Both in a plurality election and in the first round of a majority runoff election, each voter may vote for one of the three alternatives who compete for election. The action set is thus the same under both rules: $\Psi=\{A, B, C\} .^{21}$

A strategy under electoral system $S$ is a mapping $\sigma^{S}: T \rightarrow \triangle(\Psi)$, the set of probability distributions over the action set. $\sigma_{t}^{S}(\psi)$ denotes the probability that a voter with type $t$ plays action $\psi \in \Psi$ under electoral system $S$. Note the focus on symmetric strategies (i.e. voters with the same type and signal vote in the same way): this assumption is common in voting games which reflects the idea that voters are anonymous. Given a strategy $\sigma^{S}$, the expected vote share of an action $\psi$ is $\tau_{\psi}\left(\sigma^{S}\right)=\sum_{t} \sigma_{t}^{S}(\psi) \times r(t)$.

For the voting game under electoral system $S$, we analyze the set of symmetric Bayesian Nash equilibria in which voters do not play weakly dominated strategies. ${ }^{22}$ This assumption directly implies that, in the equilibria we are considering, $t_{C}$-voters necessarily vote

\footnotetext{
${ }^{18}$ Again, ties are resolved by alphabetical order.

${ }^{19}$ This includes (but is not limited to) any "realistic" restriction (e.g. the front-runner or the candidate with the largest (expected) number of supporters being more likely to win in the second round).

${ }^{20}$ For the sake of simplicity, we work under the assumption that $\operatorname{Pr}(A \mid A C)=\operatorname{Pr}(B \mid B C)$. It is a natural assumption in the sense that it is satisfied when we formally include the second round in the model and assume that there is a new draw of voters before the second round (see discussion in Bouton 2013 and Bouton and Gratton 2015).

${ }^{21}$ Given that abstaining is weakly dominated, including the possibility of abstention would not affect our results.

${ }^{22}$ The purpose of this assumption is to eliminate unreasonable equilibria in which all voters vote for the same alternative. These are equilibria because, for those strategy profiles, the probability that one ballot changes the outcome of the election is exactly zero. Voters are then indifferent about which alternative to support, even the one they like least.
} 


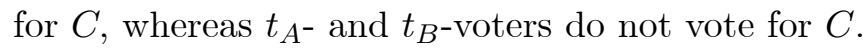

\section{Equilibrium Analysis}

In this section, we analyze the behavior of voters under both plurality and majority runoff for any electorate size, including small ones. Our objective is to show that the incentives that shape voting behavior are the same as in the case with a large electorate, which is discussed in the Appendix.

There are three main issues that complicate the analysis of voting behavior in small electorates. First, the various pivotal events affect the behavior of voters in more multifaceted ways than with large electorates. The complexity arises because the behavior of voters is not driven by only one of those events as it is with large electorates. Second, the pivot probabilities are cumbersome mathematical objects, that are not easy to manipulate, excluding when the electorate is large. Third, cardinal utilities must be accounted for. With large electorates, cardinal utilities are dwarfed by the enormous differences across pivot probabilities. For these reasons, we rely on numerical simulations for some results.

We focus on the pure strategy equilibria under both systems because it is sufficient to formally frame the debate about Duverger's Law and sincere voting. There are two types of pure strategy equilibria:

Definition 1 The sincere voting equilibrium is such that all voters vote for their most preferred candidate: $\sigma_{t_{A}}^{S}(A)=\sigma_{t_{B}}^{S}(B)=1$.

Definition 2 A Duverger's Law equilibrium is such that only two candidates obtain a positive fraction of the votes: either $\sigma_{t}^{S}(A)=1$ or $\sigma_{t}^{S}(B)=1 \forall t \in\left\{t_{A}, t_{B}\right\}$.

\subsection{Preliminaries}

Since voters are instrumental, their behavior depends on the probability that a ballot affects the final outcome of the elections, i.e. its probability of being pivotal. The pivotal events and their probabilities given a strategy are different under the two systems. In this paper, we abstract from the formal definition of those pivotal events and the computation of their probabilities. Yet, we use those objects to explain the intuition of the different 
results. Therefore, it is important to understand the different types of pivotal events under plurality and runoff.

As discussed in Myerson (2002), there is only one type of pivotal event under plurality: when a specific ballot changes the outcome of the election from a victory of alternative $i$ to a victory of alternative $j$. In contrast, in the first round of a majority runoff election there are two types of pivotal events. First, a ballot can be threshold pivotal $i / i j$. This occurs when alternative $i$ lacks one vote to obtain a strict majority of the votes in the first round. Thus, without an additional vote in favor of $i$, a second round opposing $i$ to $j$ is held. Second, a ballot may affect the final outcome if it changes the identity of the two alternatives participating in the second round. In particular, a ballot is second-rank pivotal $k i / k j$ when alternative $k$ ranks first (but does not obtain an absolute majority of the votes), and alternatives $i$ and $j$ (almost) tie for second place. An additional vote in favor of alternative $i$ allows it, instead of $j$, to participate in the second round with $k$.

\subsection{Duverger's Law Equilibria}

We can show that Duverger's Law equilibria exist under both systems even when the electorate is small (see Appendix for proof):

Proposition 1 If there are strictly more than 4 voters:

(i) Under Plurality, the two Duverger's Law equilibria always exist;

(ii) Under Majority Runoff, the two Duverger's Law equilibria exist.

The intuition is exactly the same as for large electorates. Under plurality, supporters of the alternative expected to receive (almost) no votes, do not want to waste their ballot on their most-preferred alternative which is extremely unlikely to tie for first place, and instead prefer to vote for their second-preferred alternative in order to defeat their least preferred one. Under majority runoff, supporters of the alternative expected to receive no votes, do not want to waste their ballot on their most-preferred alternative (which has no path to victory). They prefer to vote for their second-preferred alternative in order to prevent the risk of an upset victory of their least-preferred alternative in the second round.

The existence of the Duverger's law equilibria is not an artifact of one of the alternatives having a zero expected vote share. In most situations, majority voters indeed 


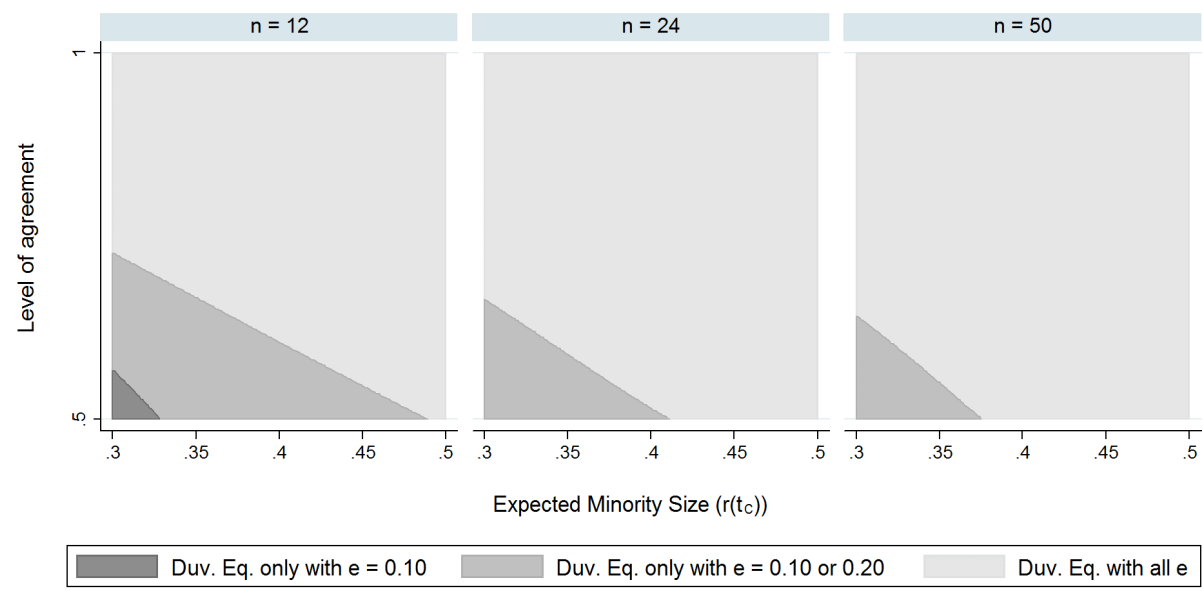

Figure 2: Existence of "A" Duverger's Law equilibrium under Runoff elections for any combination of the size of the nimority $\left(r\left(t_{C}\right)\right)$ and the level of agreement $\left(r\left(t_{A}\right) /\left(r\left(t_{A}\right)+r\left(t_{B}\right)\right)\right)$, for different sizes of the electorate and for sincere trembling frequencies by $t_{B}$-voters $\varepsilon \in\{0.1,0.2,0.5\}$.

have strict incentives to abandon their most-preferred alternative even if the probability that other majority voters vote for it is not exactly zero. We illustrate these incentives in Figure 2. This figure shows whether the duverger's law equilibria when all majority voters vote for $A$ exist when $t_{B}$-voters "tremble" by voting sincerely for $B$ with probability $\varepsilon \in\{0.1,0.2,0.5\}$, for any combination of the size of the minority $\left(r\left(t_{C}\right)\right)$ and the level of agreement $\left(r\left(t_{A}\right) /\left(r\left(t_{A}\right)+r\left(t_{B}\right)\right)\right)$ and for different sizes of the electorate. ${ }^{23}$ The figure shows that (i) Duverger's Law equilibria exist with small electorates even with large trembles, (ii) the area for which Duverger's law equilibria do not exist shrinks with $\varepsilon$, (iii) the area for which Duverger's law equilibria do not exist shrinks with $n$.

\subsection{Sincere Voting Equilibrium}

We now discuss the existence of the sincere voting equilibrium under plurality and majority runoff. Figure 3 is quite enlightening about the conditions under which the sincere voting equilibrium exists. This figure shows whether the sincere voting equilibrium exists under plurality and majority runoff for any combination of the size of the minority $\left(r\left(t_{C}\right)\right)$ and the level of agreement $\left(r\left(t_{A}\right) /\left(r\left(t_{A}\right)+r\left(t_{B}\right)\right)\right)$ and for different sizes of the electorate. It

\footnotetext{
${ }^{23}$ The utilitiy values assumed for these simulations are 1 for the top-ranked candidate, 0 for the lowestranked candidate and 0.7 for the second-ranked candidate in the case of the majority voters. The same values are assumed for the other simulations presented.
} 


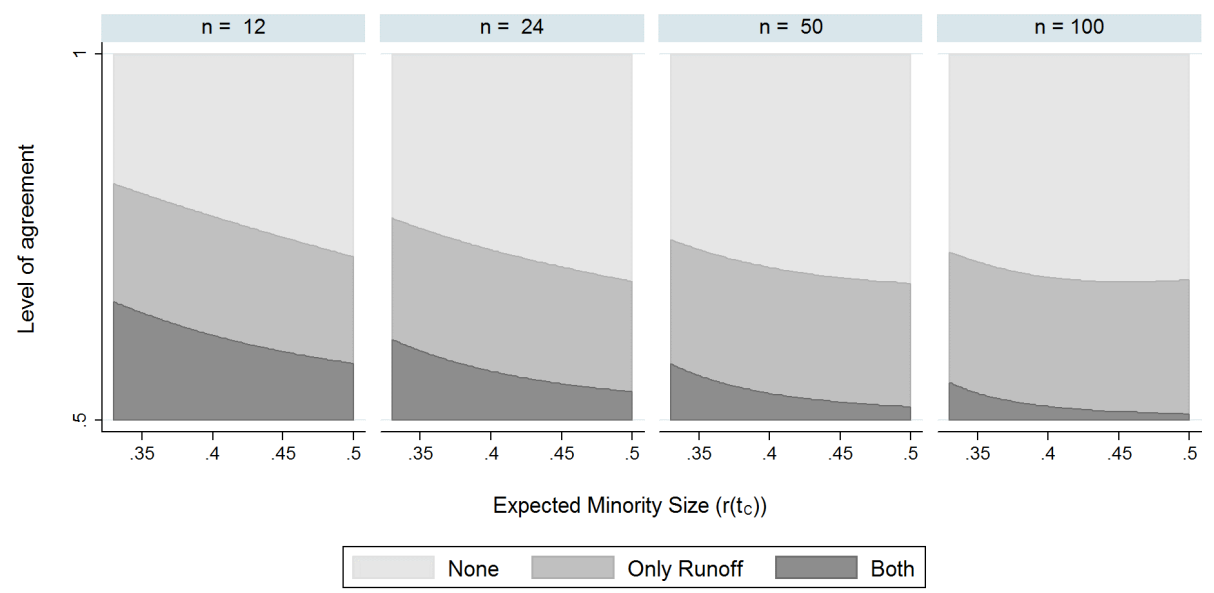

Figure 3: Existence of sincere voting equilibria under both Runoff and Plurality election for any combination of the size of the nimority $\left(r_{C}\right)$ and the level of agreement $\left(r_{A} /\left(r_{A}+r_{B}\right)\right)$ and for different sizes of the electorate.

conveys several messages. First, if the sincere voting equilibrium exists under plurality, it also necessarily exists under majority runoff, but the converse is not true. This result holds for any size of the electorate. Second, the set of parameter values for which the sincere voting equilibrium exists under plurality shrinks quite rapidly when the electorate grows large. The same is not true under majority runoff. Finally, if the level of agreement in the majority is high enough, the sincere voting equilibrium exists neither under plurality nor under majority runoff. By contrast, it can exist when the minority is expected to be quite large when the level of agreement among majority voters is sufficiently low.

\subsection{Electoral Outcomes}

Electoral outcomes can be substantially different under plurality and runoff systems. An obvious case is when voters coordinate on different equilibria under the two systems. But differences in outcomes can also emerge when voters coordinate on the same equilibrium under the two systems. In particular, there are differences when voters vote sincerely under the two systems, but no differences when they coordinate on the same Duverger's Law equilibrium. To illustrate more concretely the differences in outcomes between plurality and majority runoff, we consider some numerical examples. In particular, we focus on the parameter values of the Baseline and Low Disagreement treatments from our laboratory 
experiments (see Table 1 for the values of the parameters). The overall message is that, in comparison to plurality, majority runoff improves the selection between the two majority alternatives, $A$ and $B$. But, this comes at the cost of increasing the risk of a victory of the minority alternative, $C$.

Under plurality, only the Duverger's law equilibria exist (in both cases). In those equilibria, one majority alternative, say $A$, is supported by all majority voters. It is thus very likely to win: $76.3 \%$ in both plurality treatments. Alternative $C$ wins with the remaining probability (and $B$ never wins). The issue with those equilibria is that there is no possibility of selection between the majority alternatives: only $A$ can win, even if all majority voters prefer $B$ over $A$. If we assume that the realized distribution of preferences of voters is the true one, then although the minority alternative is defeated when it should be, the plurality system deprives majority voters of the possibility of selecting the alternative with more support.

Under majority runoff, the Duverger's law equilibria may coexist with the sincere voting equilibrium. This is the case in the Baseline configuration but not the Low Disagreement one. When voters coordinate on a Duverger's law equilibrium, the alternative receiving the support of all majority voters is again very likely to win. The probabilities are similar to those under plurality. ${ }^{24}$ Thus, the two systems are similar. By contrast, when voters coordinate on the sincere voting equilibrium, the probability that $A$ wins is sharply lower (49.91\%), while the probabilities that $B$ and $C$ wins are higher $(13.03 \%$ and $37.05 \%$ respectively). If we assume that the realized distribution in the first round is the true distribution of preferences (or closer to the true distribution than in the second round) then the higher probability of $B$ winning is a desirable feature of the majority runoff system. By incentivizing voters to reveal their preferences, majority runoff systems lead to a better selection between the majority alternatives. Now, $B$ has a chance to win, and it does when there are more majority voters who prefer $B$ than $A$. This desirable feature comes at a cost: an increase in the probability that $C$ wins either the first round or in the second. If there is a second round, which only happens when there is not a majority of voters supporting $C$ in the first round, then there is a risk of an upset victory of $C$ in the

\footnotetext{
${ }^{24}$ The difference is entirely driven by the case in which $A$ and $C$ receive 6 votes each. Due to the alphabetical tie-breaking rule, $A$ wins in that case under plurality. By contrast, under runoff, no alternative wins outright. In the second round, both $A$ and $C$ win with positive probability.
} 
second round. Such victories of $C$, which we view as socially undesirable, happens $13.01 \%$ of the time: when $C$ participate in the second round and wins. This is to be compared to the higher probability of a victory of $B$, which increases from $0 \%$ to $13.03 \%$ of the time. ${ }^{25}$

\section{$5 \quad$ Experimental Design and Procedures}

To test our theoretical predictions, and in particular, to determine if preference revelation differs as a function of the type of electoral system, we conducted controlled laboratory experiments. Subjects played a game with the same structure as presented in Section 3. We manipulated the relative support of each group of voters and the voting rule in a between-subjects design. In particular, we manipulated the level of agreement in the majority, the size of the minority, and the type of electoral system.

Design. In all treatments, participants interacted in the same group of 12 voters and played the game for 60 rounds. ${ }^{26}$ Alternatives $A, B$, and $C$ were labeled Green, Purple and Yellow, respectively. Thus, Green and Purple were the two majority candidates and Yellow was the (expected) Condorcet loser. ${ }^{27}$ In the beginning of each round, participants were assigned a type by drawing (with replacement) a ball from a hypothetical urn which contained a commonly known composition of green, purple and yellow balls (and the color of the ball indicates the most preferred choice of the voter). The particular composition of balls was one of the treatment variables in our experiments. In the Baseline (B) set of parameters, the urn consisted of 34 Green $\left(t_{A}\right), 22$ Purple $\left(t_{B}\right)$, and 44 Yellow $\left(t_{C}\right)$ balls. In the Low Disagreement (LD) set we kept the (expected) size of the minority fixed, and increased the agreement between majority voters, by having 43 Green $\left(t_{A}\right)$ balls and 13 Purple $\left(t_{B}\right)$ ones. For the sake of expositional clarity, in the remainder of the paper, we use the same wording as in the theory section when referring to alternatives $(A, B$, and $C)$ and types of voters $\left(t_{A}, t_{B}\right.$, and $\left.t_{C}\right)$.

\footnotetext{
${ }^{25}$ In order to compare the social desirability of plurality outcomes with majority rule outcomes, we assume that the revealed preferences in the first stage of a majority rule election are equivalent to those in a plurality rule election

${ }^{26}$ Repeated game effects are unlikely in our setup since types are redrawn in every period and payment is made for only a few randomly drawn periods. We used fixed matchings in order to allow voters to better learn the strategies of others and coordinate. For example, Forsythe et al. (1993, 1996) observe that Duverger's Law equilibria emerge more easily among voters with a common history - see also Rietz (2008) and Bouton et al. (2016).

${ }^{27}$ Since the realized distribution of voter preferences was subject to randomness, Yellow is the Condorcet loser in expectation, not necessarily in actuality.
} 


\begin{tabular}{lllccccccccc} 
Treat. & \multicolumn{1}{c}{ Parameters } & Rule & ra & rb & rc & pAB & pAC & pBC & Groups & Sinc & Duv \\
\hline R_B & Baseline (B) & Runoff & 34 & 22 & 44 & 78 & 76 & 76 & 6 & $\checkmark$ & $\checkmark$ \\
P_B & Baseline (B) & Plurality & 34 & 22 & 44 & - & - & - & 5 & & $\checkmark$ \\
R_LD & Low Disagr. (LD) & Runoff & 43 & 13 & 44 & 96 & 76 & 76 & 5 & & $\checkmark$ \\
P_LD & Low Disagr. (LD) & Plurality & 43 & 13 & 44 & - & - & - & 5 & & $\checkmark$ \\
\hline
\end{tabular}

Table 1: Main treatments overview.

The second variable that we varied across treatments was the electoral system: either plurality or majority runoff. Under either voting rule, after learning their type, participants voted for one of the three alternatives. Under Plurality $(\mathrm{P})$, the alternative with the most votes won the election, with ties broken alphabetically. Under Runoff (R) elections, one of the alternatives won if it received strictly more than $50 \%$ of the votes. In case no alternative won in the first round, the two alternatives with the most votes advanced to the second round which, in line with the theoretical setup, was computerized. Participants knew beforehand the probabilities of victory of each alternative in the second round under all possible scenarios. These probabilities were computed as if there was a new draw of 12 individuals from the same distribution as that of the initial urn, with all participants playing their dominant strategy (and type $t_{C}$ abstaining when $A$ and $B$ proceeded to the second round). ${ }^{28}$

The payoffs were the same in all treatments: $t_{A}$ and $t_{B}$-voters received $\$ 11$ if their top choice was elected, $\$ 8$ if their second-preferred alternative was elected, and $\$ 1$ if their least-preferred was elected. $t_{C}$-voters received $\$ 11$ if their top choice was elected, and $\$ 1$ otherwise.

Table 1 summarizes the main treatments and indicates the number of groups of 12 used for each one. It also indicates which types of (pure strategy) equilibria exist: while Duverger's Law equilibria exist in all treatments, the sincere voting equilibrium exists only in the $\mathrm{R} \_\mathrm{B}$ treatment_-i.e. under the runoff rule with the baseline parameter configuration.

\footnotetext{
${ }^{28}$ We chose to computerize the second stage for two reasons. First, in a pilot session using an alternative design with an additional group of 12 subjects who only voted in the second round, we found that the dominant strategy of voting for the preferred choice was played more than $95 \%$ of the time. Therefore, our design reduced the cost with respect to the alterantive design while conserving the properties of the seocnd round. Second, a non-computerized second round might have induced subjects to converge to the Duverger's Law equilibria in order to minimize the length of the experiment. Our design has additional interesting and useful features. In particular, flexibility on the realized probabilities in the second round allowed us to vary the second round probabilities without changing the instructions for the first round. We explore this possibility in some of the alternative treatments, discussed in the next sections.
} 
Procedures. Experimental sessions for all treatments were conducted at New York University's Center for Experimental Social Science (CESS) between October 2017 and April 2018. We conducted a total of 38 sessions, with either 12 or 24 subjects. No subject participated in more than one session. Subjects were recruited through the online recruitment software h-root (Bock, Nicklisch, and Baetge, 2012), and the experiment was programmed and conducted using the software z-Tree (Fischbacher, 2007). All sessions were organized under the same procedure: subjects received detailed written instructions, which an experimenter read aloud (see Appendix A3). Before starting the experiment, subjects were asked to answer a questionnaire to confirm their full understanding of the experimental design. After the questionnaire, subjects began to play. At the end of each round, each subject received the following information: (i) the group decision, (ii) the number of votes for each alternative, and (iii) her payoff for that period.

To determine the payment at the end of the experiment, the computer randomly selected three periods and subjects were paid the total sum earned in these three periods. In total, subjects earned an average of $\$ 35.03$, a minimum of $\$ 10$, and a maximum of $\$ 40$. All these figures include a show-up fee of $\$ 7$.

\section{Experimental Results}

This section summarizes the voting behavior observed in the laboratory. The bottom line is that coordination forces appear to be strong both under plurality and majority runoff. Voters indeed (partially) coordinate on the Duverger's Law $A$ equilibrium under both systems. Yet, some voters appear to always vote sincerely, and others to always voter Duvergerian.

Note that we report parametric tests of differences in choices and outcomes based on regression analysis summarized in Tables 8-13 in Appendix A4. These regressions cluster standard errors at the matching group level, and in some specifications, we control for individual voter characteristics. ${ }^{29}$ If they lead to different conclusions, we also report non-parametric tests, using averages at the group level as their unit of analysis.

\footnotetext{
${ }^{29}$ The vector of covariates includes subjects' gender, age, years in school, a level of risk, a level of trust, and dummies for experience participating in experiments and interest in politics. Additional specifications control for whether the minority alternative $(C)$ won the previous election or a count variable indicating the number of elections previously won by the minority alternative.
} 


\begin{tabular}{|c|c|c|c|c|c|c|c|}
\hline & & \multicolumn{3}{|c|}{ Baseline } & \multicolumn{3}{|c|}{ Low disagreement } \\
\hline & & $\% \mathrm{~A}$ & $\% \mathrm{~B}$ & $\% \mathrm{C}$ & $\% \mathrm{~A}$ & $\% \mathrm{~B}$ & $\% \mathrm{C}$ \\
\hline \multirow[t]{3}{*}{ Plurality } & $t_{A}$ & 99.1 & 0.41 & 0.49 & 98.17 & 1.57 & 0.26 \\
\hline & $t_{B}$ & 75.25 & 24.14 & 0.62 & 71.49 & 27.92 & 0.59 \\
\hline & $t_{C}$ & 1.47 & 0.89 & 97.64 & 2.82 & 1.22 & 95.97 \\
\hline \multirow[t]{3}{*}{ Runoff } & $t_{A}$ & 97.21 & 2.38 & 0.41 & 97.34 & 2.14 & 0.52 \\
\hline & $t_{B}$ & 58.72 & 40.26 & 1.01 & 70.55 & 28.6 & 0.85 \\
\hline & $t_{C}$ & 1.34 & 0.97 & 97.69 & 1.58 & 0.69 & 97.73 \\
\hline
\end{tabular}

Table 2: Aggregate behavior in main treatments.

Aggregate voting behavior. Table 2 summarizes aggregate voting behavior in the four treatments. Two clear patterns emerge in all treatments. First, and in line with the theoretical predictions, $t_{C}$-voters overwhelmingly play their weakly dominant strategy to vote for alternative $C$. The frequency of playing this strategy is above $95 \%$ in all the treatments and there are no significant differences across electoral systems ( $p$-value $=0.829$ for $\mathrm{B}$ treatments and $\mathrm{p}$-value $=0.121$ for $\mathrm{LD}$ treatments $).{ }^{30}$ Second, $t_{A \text {-voters }}$ massively choose alternative $A$ : the frequency is above $97 \%$ in all the main treatments and there are no significant differences across electoral systems ( $p$-value $=0.137$ for $B$ treatments and p-value $=0.615$ for $\mathrm{LD}$ treatments). As a consequence, it is clear that there is no convergence to the Duverger's Law equilibrium in which all majority voters choose alternative $B$. If there is convergence to a Duverger's Law equilibrium it will be to the one in which majority voters coordinate on alternative $A .{ }^{31}$ This depends on the behavior of $t_{B}$-voters.

Under plurality, if $t_{B}$-voters correctly anticipate the behavior of $t_{A^{-}}$and $t_{C}$-voters, then they face no trade-off: they should abandon their favorite alternative and vote for alternative $A$. This is true even if all other $t_{B}$-voters vote sincerely for $B$. And indeed, we find that $t_{B}$-voters play this best response a bit more than $70 \%$ of the time. Nevertheless, the frequency with which they vote for their favorite alternative is non-negligible: $24.14 \%$ in $\mathrm{P}_{-} \mathrm{B}$ treatments and $27.92 \%$ in $\mathrm{P} \_\mathrm{LD}$ treatments. However, this difference is not

\footnotetext{
${ }^{30}$ In order to test for significant differences, we regress the probability of voting sincerely by $t_{A}$-voters in the $\mathrm{B}$ treatments with a dummy variable indicating if the voting rule is runoff (controlling for a number of observables), and we test whether this coefficient is significantly different from zero or not. We use a similar procedure to test for differences in behavior across treatments for $t_{B^{-}}$and $t_{C}$-voters. In every case, random effects models are estimated, to exploit the temporal nature of the data.

${ }^{31}$ Given the co-existence of two Duverger's law equilibria, it is somehow surprising that majority voters always coordinate behind alternative A. One potential explanation is that the status of A as the majority alternative with the higher (expected) support in the electorate, i.e., $r\left(t_{A}\right)>r\left(t_{B}\right)$, may makes the Duverger's law equilibrium A the focal equilibrium.
} 


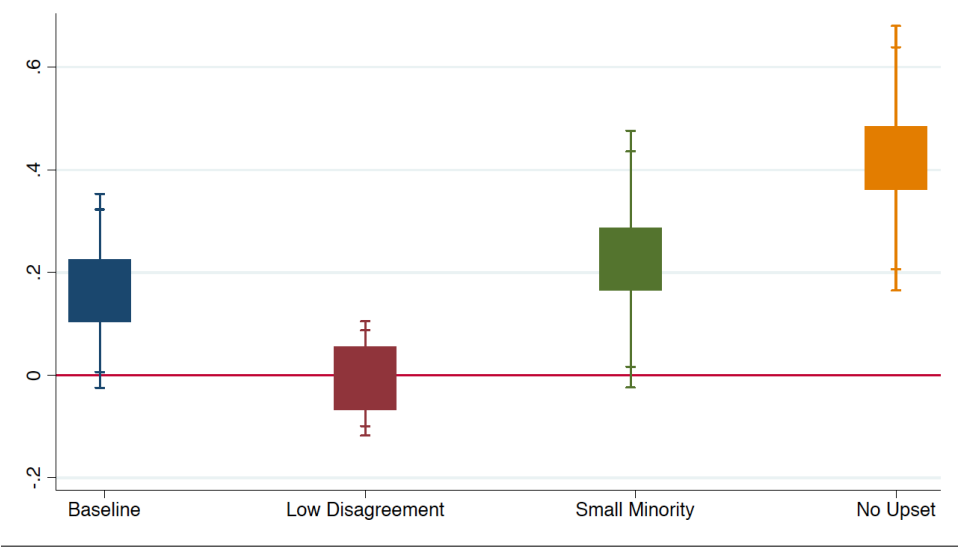

Figure 4: Treatment effects of the voting rule on the probability of strategic voting by

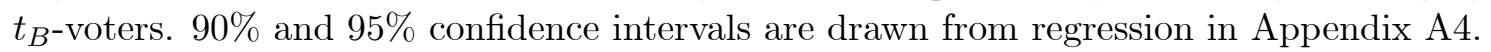

significantly different from $0(\mathrm{p}$-value $=0.294)$.

In treatment $R_{-} L D$, if they correctly anticipate the behavior of $t_{A^{-}}$and $t_{C^{-}}$voters, the incentives for $t_{B}$-voters to vote sincerely under runoff are similar to those under plurality: the sincere voting equilibrium does not exist. In this treatment, $t_{B}$-voters vote sincerely only $28.6 \%$ of the time. Figure 4 displays the treatment effects of the voting rule on behavior of $t_{B}$-voters (in order to save space, it also includes the coefficient for two additional treatments, SM and NU, which we describe in Section 7). As the figure shows, in the LD treatments, the frequency of sincere voting by $t_{B}$-voters under runoff is not significantly different than under plurality $(\mathrm{p}$-value $=0.727)$. Furthermore, as Figure 5 shows, the amount of sincere voting decreases over time in all groups. ${ }^{32}$

Unlike in the other treatments, in treatment $\mathrm{R}$ B, the sincere voting equilibrium and the Duverger's law equilibria coexist. Taking as given the behavior of $t_{A}$-voters (who almost always vote for $A$ ), this means that there are two equilibria in pure strategies: one in which $t_{B}$-voters all vote for $A$, and another one in which they all vote for $B$. In this treatment, $t_{B}$-voters voted for their favorite candidate $40.26 \%$ of the time, which contrasts with the $24.14 \%$ observed under plurality. Despite the size of the difference, it is not significant with non-parametric tests (Wilcoxon, p-value $=0.144$ ). But, as Figure 4 shows, we find a significant effect at the $10 \%$ confidence level in the regression analysis. Table 8 in

\footnotetext{
${ }^{32}$ In the R_LD treatment, sincerity of $t_{B}$-voters in group 1 , for instance, decreases from $71 \%$ on average during the first five periods, to $33 \%$ over the last five; for group 2 it goes from $57 \%$ to $40 \%$; from $62 \%$ to $29 \%$ for group 3 ; from $33 \%$ to $14 \%$ for group 4 ; and from $29 \%$ to $10 \%$.
} 


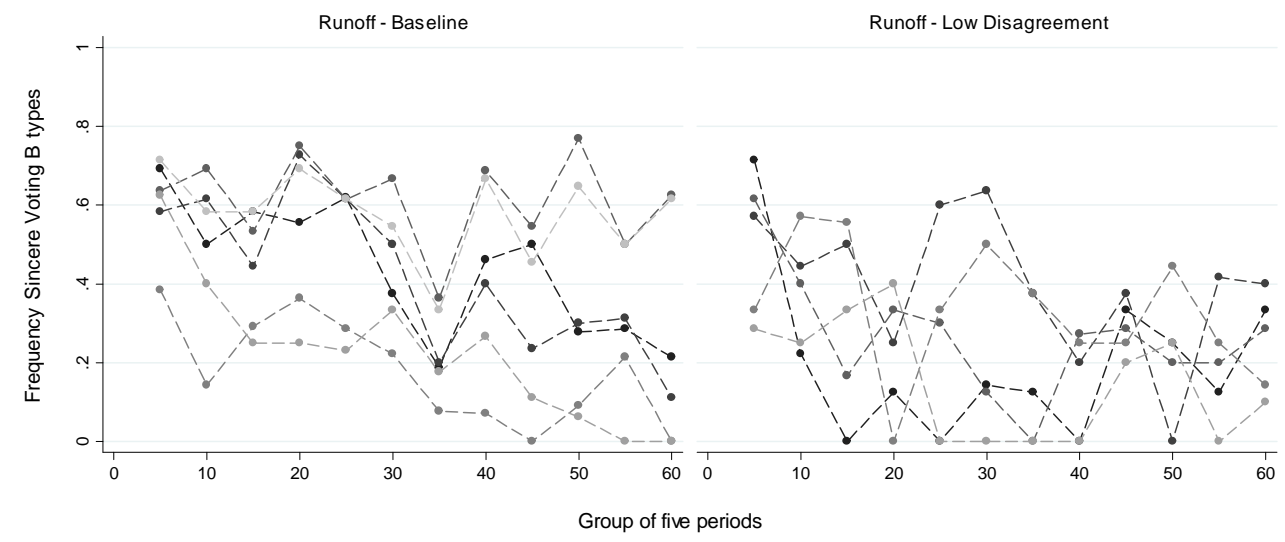

Figure 5: Temporal evolution of sincere voting by $t_{B}$-voters in $\mathrm{R}_{-} \mathrm{B}$ and $\mathrm{R} \_\mathrm{LD}$ treatments.

the Appendix shows that the runoff treatment always has a positive and significant effect, of about 18 percentage points, on the sincerity of $t_{B}$-voters. Overall, it seems that there is only weak evidence that, in the B treatments, runoff elections favor sincere voting by $t_{B}$ voters. But we remain far from the level predicted in case of convergence to the sincere voting equilibrium.

Given the multiplicity of equilibria, it could be that some groups coordinate on the sincere voting equilibrium while others coordinate on the Duverger's Law $A$ equilibrium. We find that this is not the case, although there is some heterogeneity. The average percentages of sincere voting among $t_{B}$-voters in the 6 groups are $20.22,21.34,40.63,43.58$, 58.23 and 61.90 . Sincere voting is a best response when the other $t_{B}$-voters vote sincerely at least $58.45 \%$ of the time. ${ }^{33}$ Therefore, in most groups, the best response of $t_{B}$-voters was to not vote sincerely and vote for $A$ instead (again assuming they anticipate correctly the behavior of other voters, including other $t_{B}$-voters). Moreover, these incentives increased over time since the frequency of sincere voting decreased in the later periods: the frequency of sincere voting was $54.00 \%$ in the first 10 periods and $27.10 \%$ in the last 10 periods. Despite some heterogeneity on the levels and rates of convergence, we find that the amount of sincere voting decreases over time in most groups (i.e., 4 out of 6 ). Figure 5 illustrates this result. Note that, even in the two groups in which sincere voting does not decrease over time, the average frequency of sincere voting among $t_{B}$-voters in the second part of

\footnotetext{
${ }^{33}$ Figure 13 in the Appendix displays the utilities of $t_{B}$-voters from voting either $\mathrm{A}$ or $\mathrm{B}$, for all treatments.
} 
the experiment (or even the last 10 or 20 periods) is below $58.45 \%$ : sincere voting is thus not a best response for $t_{B}$-voters. ${ }^{34}$

Overall, the analysis of aggregate voting behavior highlights a convergence to the Duverger's law equilibrium $A$ under both plurality and runoff. Yet, this convergence is only partial. Analyzing the voting behavior at the individual level allows for a better understanding of this phenomenon.

Individual Behavior. Figure 6 displays a representation of individual behavior, focusing on behavior of $t_{B}$-voters. The horizontal (vertical) axis reports the frequency of sincere voting in the first (second) half of the experiment. The diameter of each hollow circle in the graph corresponds to the number of subjects who played at those frequencies: the larger this number, the larger the diameter.

Figure 6 shows several interesting patterns. First, most 'bubbles' are below the 45 degree line, indicating that the frequency of sincere voting decreased for most subjects. The frequencies of subjects who strictly (weakly) decrease the percentage of sincere voting in the second half are $35 \%(95 \%), 33 \%(88 \%), 51 \%(86 \%), 43 \%(92 \%)$ in treatments P_B, R_B, $P_{-} L D$ and $R_{-} L D$ respectively. Second, we observe two opposite clusters along the 45 degree line: voters who played (almost) always sincerely (upper right corner) and voters who (almost) always chose $A$ (lower left corner). In the second half of the experiment, in the $\mathrm{P}_{-} \mathrm{B}$ treatment, $15.0 \%$ of the $t_{B}$ voters vote sincerely in all periods, and $45.0 \%$ vote for $A$ (Duvergerian) in all periods. For the $\mathrm{R}_{-} \mathrm{B}$ treatment, these percentages are $8.3 \%$ and $23.6 \%$ respectively, or $22.2 \%$ and $41.7 \%$ if we relax the condition to playing the respective strategies at least $80 \%$ of the time. Similar patterns hold for the $\mathrm{P}_{\text {_ }} \mathrm{LD}$ and R_LD treatments, but with smaller fractions of "always Duvergerian" in the former, and larger in the latter.

This duality is relevant for the emergence of Duverger's law equilibria. On the one hand, the existence of always sincere voters should weigh against the emergence of a Duverger's law equilibrium, and in favor of the sincere voting equilibrium. Yet, the Duverger's law equilibrium $A$ exists under plurality ( $\mathrm{P}_{-} \mathrm{B}$ treatment) regardless of the fraction of $t_{B^{-}}$ voters that always vote sincere, and exists under runoff ( $R_{-} B$ treatment) when at most

\footnotetext{
${ }^{34}$ This threshold is based on the assumption of risk neutrality. However, laboratory participants typically exhibit moderate risk aversion. As Figure 12 (in Appendix A5) indicates, the threshold of 58.45\% increases with risk aversion.
} 

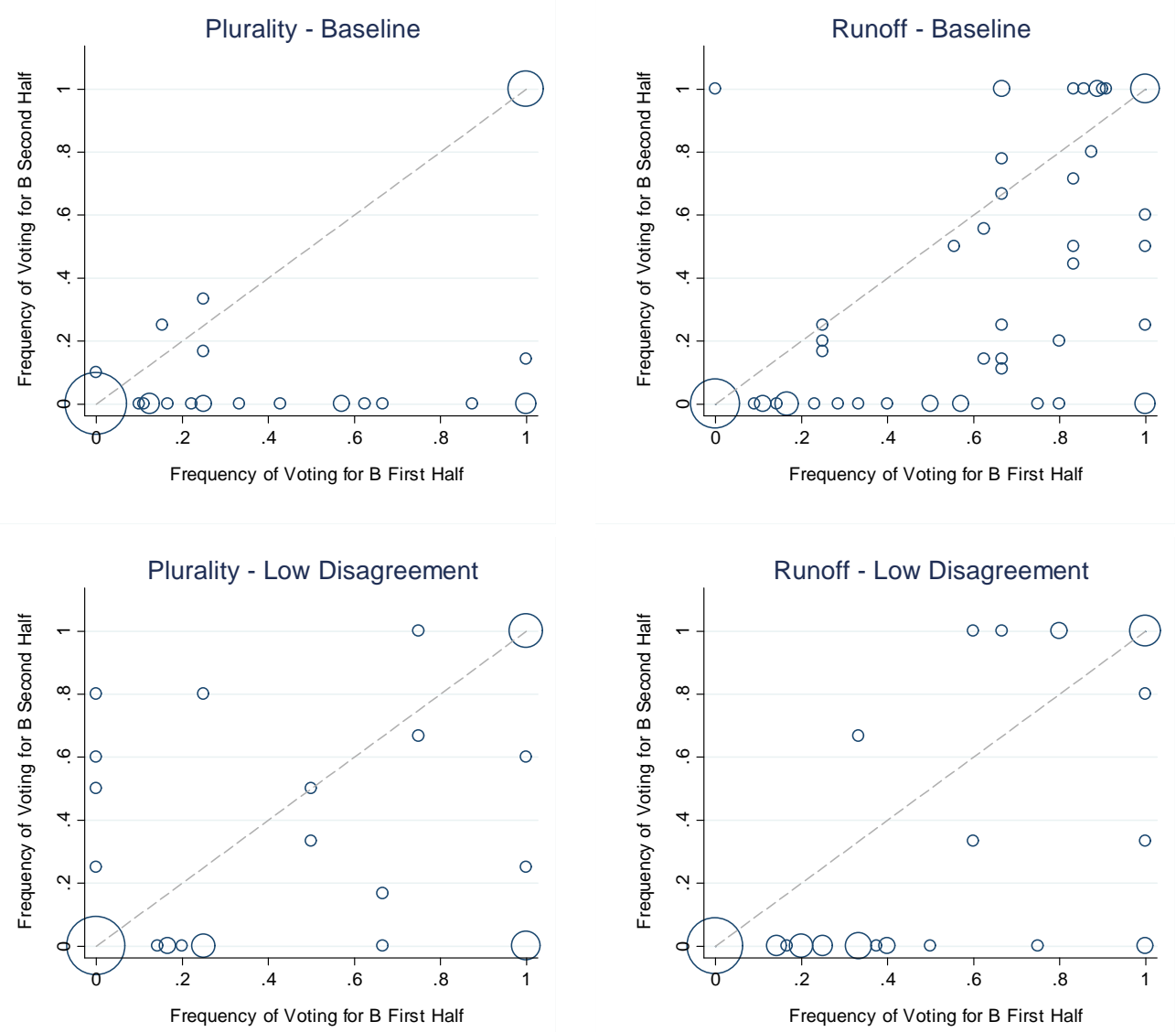

Figure 6: Individual behavior in the main treatments. 
$63.64 \%$ of $t_{B}$-voters always vote sincere. On the other hand, the existence of "always Duvergerian" voters should weigh against the emergence of the sincere voting equilibrium, and in favor of the Duverger's law equilibrium $A$. And indeed, with runoff ( $\mathrm{R} \_\mathrm{B}$ treatment), sincere voting is not a best response for $t_{B}$-voters when at least $42 \%$ of the $t_{B}$-voters vote for $A$ no matter what. Thus, the presence of "always Duvergerian" voters appears key to explain the predominance of Duverger's law equilibria in runoff. And the presence of "always sincere" voters explains why the convergence to Duverger's law equilibria is only partial.

The obvious next step is to understand the reasons why some voters always vote sincerely or Duvergerian. One possible reason for the always Duvergerian behavior is a high level of risk aversion. Indeed, as Figure 12 (in Appendix A5) shows, the sincere voting equilibrium exists in none of the treatments if voters are sufficiently risk averse. While the aggregate level of risk aversion that prevents the existence of the sincere voting equilibrium seems unreasonably high, it can still be that some $t_{B}$-voters are sufficiently risk averse to prefer voting for $A$ even when all other voters choose sincerely. To explore this possibility, for $t_{B}$-voters, we estimated a linear regression where the outcome is a dummy indicating if the subject always voted for $A$, and as regressors we used a battery of self-declared individual-level traits, including: age, gender, years in college, measures of risk aversion and trust, experience participating in experiments and interest in politics. The first panel of Figure 7 shows the coefficients of that regression. Risk aversion does not seems to distinguish always Duvergerian voters from other voters. In fact, our measure of risk aversion is distributed quite similarly for always Duvergerian voters and the entire population of $t_{B}$-voters. The only distinguishing individual characteristic of always Duvergerian voters is gender: women are under-represented in that group. The proportion of women among always Duvergerian voters is $31.67 \%$ (while the percentage of women in these treatments is $45.31 \%$ ).

Another possible explanation for the always Duvergerian behavior is that some voters simply misunderstand the influence of their ballot on the outcome of the election. Incentives to coordinate behind the stronger majority candidate are indeed high for voters who wrongly believe that they can prevent an outright victory of $C$ in the first round (as in plurality). But, if $C$ obtains 7 or more votes, then a vote for $A$ or $B$ cannot prevent $C$ 's 
(i) Always Duvergerian

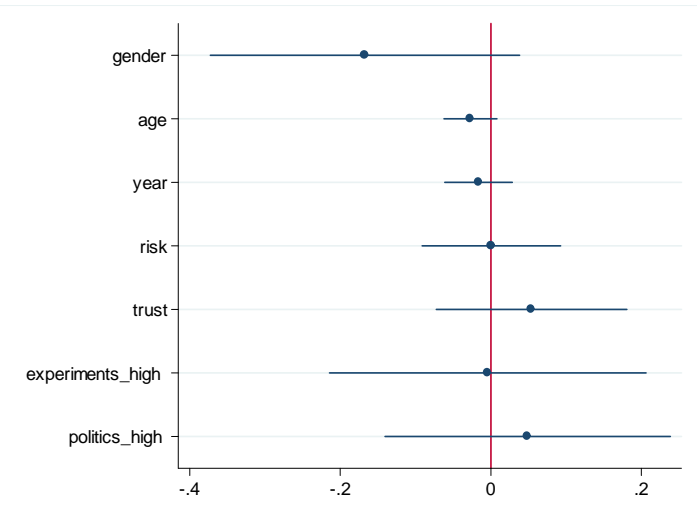

(ii) Always Sincere

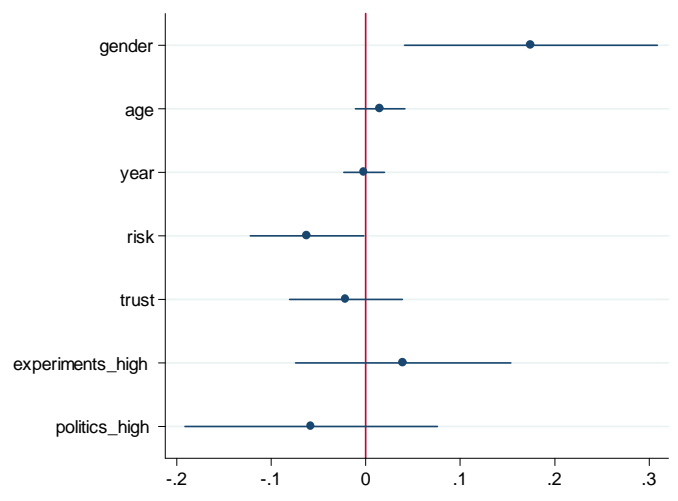

Figure 7: Individual characteristics and "always Duverger" and "always sincere" behavior.

victory. The only effect of coordination in the first round on $C$ 's probability of victory is through the decreased likelihood that a second round takes place, in which an upset victory of $C$ can occur. The additionnal treatments summarized in Section 7 give some credence to this possible explanation: even when the risk of an upset victory of $C$ in the second round is essentially null, some majority voters continue to vote always Duvergerian.

We now explore possible reasons for the always sincere behavior. The second panel of Figure 7 shows the coefficients of a linear regression where the outcome is a dummy indicating if the subject always voted for $B$, and as regressors we used the same individuallevel traits as above. Note that risk aversion does not significantly distinguish always sincere voters from others. Again, the only distinguishing individual characteristic of always sincere voters is gender: women are over-represented in that group. The proportion of women among always sincere voters is $64.41 \%$ (compared to an average of $45.31 \%$ ).

Beyond (a lack of) risk aversion, we see, at least, two other possible reasons for the always sincere behavior. First, it might be explained by an expressive motive (see Schuessler 2000). That is, subjects might have preferences for expressing their true preferences rather than being guided by instrumental incentives. An alternative explanation is lack of sophistication (the so-called "naive" voters in the literature who face cognitive limitations, see Bendor, et al. 2011) and focal strategies. That is, subjects might have cognitive difficulties in calculating the expected payoffs of voting for different alternatives and use the focal strategy of voting sincerely. Unfortunately, we do not have measures for such individual characteristics. Nevertheless, there are reasons to believe those explanations do 


\begin{tabular}{|c|c|c|c|c|c|c|c|c|}
\hline & & & \multicolumn{3}{|c|}{ Baseline } & \multicolumn{3}{|c|}{ Low Disaggr. } \\
\hline & & & $\% \mathrm{~A}$ & $\% \mathrm{~B}$ & $\% \mathrm{C}$ & $\% \mathrm{~A}$ & $\% \mathrm{~B}$ & $\% \mathrm{C}$ \\
\hline \multirow[t]{3}{*}{ Plurality } & Realized & All periods & 68.0 & 0.0 & 32.0 & 70.5 & 0.0 & 29.5 \\
\hline & & Second Half & 70.5 & 0.0 & 29.5 & 70.7 & 0.0 & 29.3 \\
\hline & Theory & Duv. Eq. & 76.3 & 0.0 & 23.7 & 76.3 & 0.0 & 23.7 \\
\hline \multirow[t]{4}{*}{ Runoff } & Realized & All periods & 64.9 & 1.8 & 33.2 & 69.5 & 0.1 & 30.4 \\
\hline & & Second Half & 65.9 & 1.2 & 32.9 & 69.3 & 0.0 & 30.7 \\
\hline & Theory & Duv. Eq. & 70.8 & 0.0 & 29.2 & 71.2 & 0.0 & 28.8 \\
\hline & & Sincere & 49.7 & 13.0 & 37.2 & - & - & - \\
\hline
\end{tabular}

Table 3: Simulated outcomes in main treatments. All periods uses the average frequencies for each while Second Half uses the averages only for the second half. The equilibrium benchmarks are based on the simulated data.

not explain fully the behavior of always sincere voters. Indeed, the fact that the size of the groups of always sincere voters varies across treatments suggests that at least some of these voters react to their electoral environment when deciding how to vote. Moreover, these variations in size are in line with the predictions of the model: more always sincere voters in the $\mathrm{R}_{-} \mathrm{LD}$ and the $\mathrm{R}_{-} \mathrm{B}$ treatments.

Outcomes. As we explained in Section 4.4, electoral outcomes can be substantially different under plurality and runoff. Yet, differences should not arise when voters play the same Duverger's Law equilibrium under both systems. Given the (partial) convergence to a Duverger's Law equilibrium $A$ under both systems, it is not surprising that we find essentially no differences in outcomes across treatments.

In order to produce comparable numbers between treatments and institutions, we present the result of simulations on outcomes based on individual average behavior. That is, for each group, we simulate 10,000 decisions for each group based on the individual behavior of each voter. ${ }^{35}$ Table 3 presents both the theoretically and the simulated probabilities of victory of the different alternatives under our treatments.

As Table 3 shows, outcomes do not differ much between electoral systems and sets of parameters. The realized probabilities of victory are actually close to the theoretical probabilities. Regression analysis also highlights small differences across treatments. Table 14

\footnotetext{
${ }^{35}$ We ran the simulations as follows. First, we computed individual voting frequencies for each subject (for the whole experiment or the second half). Then, for each of the 10,000 decisions, we (i) randomly assigned a type to each voter, (ii) simulated a vote for each voter given their voting frequencies given their type, and (iii) aggregated the vote. We ran this process independently for each group and then aggregated for each different treatment.
} 
in the Appendix reports the results of random effects regressions, in which we regress the probability of victory of each candidate on a runoff indicator and for the different parameter configurations. ${ }^{36}$ Columns 1-3 show that in the B treatments, the electoral system has no effect on the probability that $A$ wins. In contrast, a victory of $B$ is 1 percentage point more likely (significant at the $5 \%$ level) in runoff elections, while $C$ wins with a probability of 5 percentage points lower (significant at the $10 \%$ level) in runoffs. For the LD treatments, the probabilities of $A$ and $C$ winning do not vary significantly under the two electoral systems. ${ }^{37}$

The previous discussion highlights that, in our laboratory experiments, runoff elections do not differ significantly from plurality elections in terms of outcomes (and hence welfare). Yet, this conclusion overlooks one important difference between the two systems: voters may have to turn out twice in a runoff election. And indeed, we find that a second round was necessary $47.78 \%$ of the time in the $\mathrm{R} \_\mathrm{B}$ treatment, and $33 \%$ of the time in the $\mathrm{R}_{-} \mathrm{LB}$ treatment. As Figure 8 shows, under the $\mathrm{R}_{-} \mathrm{B}$ treatment, the frequency of a second round decreased over time (in concert with the decrease in sincere voting by $t_{B^{-}}$ voters). Thus, while the coordination on the Duverger's Law equilibrium is sufficient to prevent differences in outcomes (and, in particular, the victory of alternative $B$ when there are many $t_{B}$-voters in the electorate), it is not sufficient to ensure a systematic outright victory of either $A$ or $C$. This conclusion does not fare well for the runoff electoral system. Indeed, our results suggests that the extra costs it requires are not justified by a better aggregation of preferences.

\section{Additional Treatments}

The results of the experiments summarized in the previous section highlights small institutional differences between plurality and runoff elections. The main reason is that, under both electoral systems, voters converge (partially) to the same Duverger's Law equilibrium. The fact that sincere voting is not more focal under runoff is somehow puzzling. It has indeed been shown in previous experiments that sincere voting is quite prominent (see, for example, Morton and Rietz, 2007). Moreover, in the first period of our runoff

\footnotetext{
${ }^{36}$ As before, standard errors are clustered at the group level.

${ }^{37}$ We cannot estimate analogous models for the probability of $B$ winning the election, because under the LD treatment, $B$ never wins an election.
} 

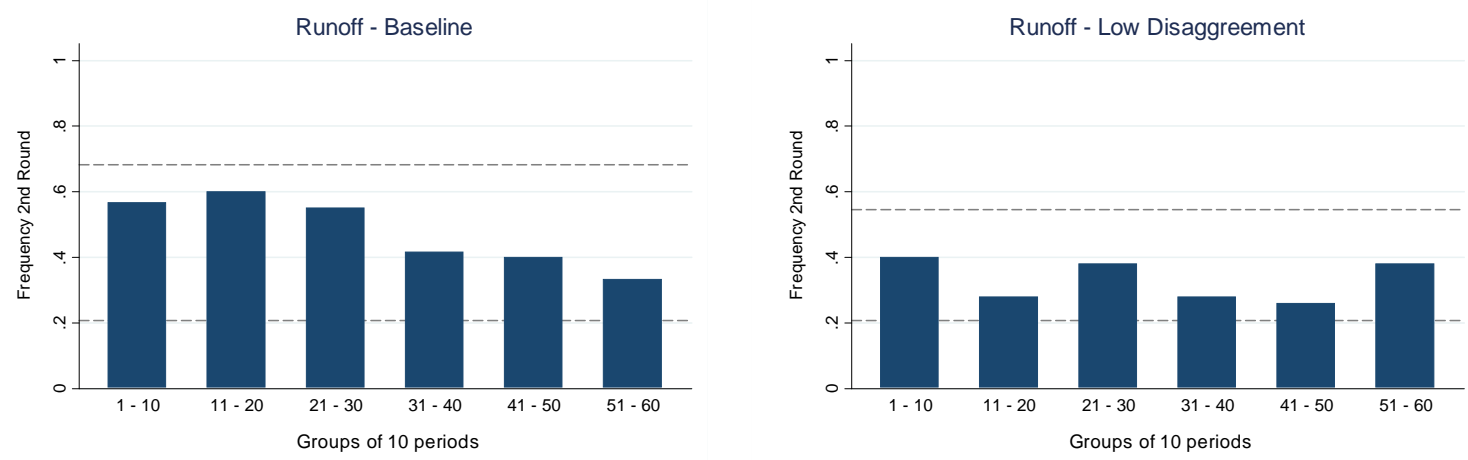

Figure 8: Probability of reaching the second round over time. The upper (lower) gray dashed line indicates the theoretical probability of reaching the second round in the sincere voting (Duverger's Law) equilibrium.

treatments, the amount of sincere voting among $t_{B}$-voters was $67 \%$. This means that sincere voting was a best response for all $t_{B}$-voters.

In this section, we summarize additional treatments designed to explore the robustness of the finding that coordination forces are strong under runoff elections. We do so by increasing the incentives to play the sincere voting equilibrium. We find that, although the frequency of sincere voting increases, there is a non-negligible fraction of voters who always vote Duvergerian. We find suggestive evidence that those voters behave in such a way because they fail to understand the effect of their ballot in the first round of a runoff election.

\subsection{Experimental Design}

We designed two additional treatments with (i) the same basic structure and procedures as the ones described in section 5, and (ii) sets of parameters that are related to those of the baseline treatment. In those treatments, described in Table 4, the incentives of majority voters to vote sincerely are stronger than in the baseline treatment.

In the Small Minority (SM) treatment, we reduced the size of the minority, $r\left(t_{C}\right)$, by 5 percentage points, to $39 \%$. We also increased $r\left(t_{A}\right)$ and $r\left(t_{B}\right)$ as close as possible to proportionality, given the constraint of using integer numbers with the subjects, to $37 \%$ and $24 \%$, respectively. The decrease in the expected size of the minority increases the incentives of majority voters to vote sincerely in two ways. First, when majority voters vote sincerely, it is more likely that the second round opposes $A$ and $B$, the two majority 


\begin{tabular}{cccccccccccc} 
Treat. & \multicolumn{1}{c}{ Parameters } & Rule & ra & rb & rc & pAB & pAC & pBC & Groups & Sinc & Duv \\
\hline R_SM & Small Min. (SM) & Runoff & 37 & 24 & 39 & 78 & 86 & 86 & 5 & $\checkmark$ & $\checkmark$ \\
P_SM & Small Min. (SM) & Plurality & 37 & 24 & 39 & - & - & - & 5 & $\checkmark$ & $\checkmark$ \\
R_NU & No Upset (NU) & Runoff & 34 & 22 & 44 & 78 & 99 & 99 & 5 & $\checkmark$ & $\checkmark$ \\
\hline
\end{tabular}

Table 4: Overview of additional treatments.

candidates. Second, the probability of an upset victory of $C$, the minority candidate, in the second round is lower. As a result, the incentives to vote sincerely are stronger than in the baseline model: if $t_{A}$ and $t_{C}$-voters vote sincerely, the minimal percentage of sincere voting by $t_{B}$-voters that makes sincere voting a best response for those voters is $47.87 \%$, compared to a threshold of $58.45 \%$ in the baseline treatment. We conducted sessions with these parameters under both plurality and runoff elections. Unlike the previous treatments, in this case sincere voting is also an equilibrium under plurality.

In the No Upset (NU) treatment, we reduced drastically the probability of an upset victory of $C$ in the second round, by setting $\operatorname{Pr}(A \mid A C)=\operatorname{Pr}(B \mid B C)=99 \%$. All other parameters remain at the baseline level. As a result, the incentives to vote sincerely are very strong: if $t_{A}$ and $t_{C}$-voters vote sincerely, sincere voting is the best response for those voters as long as other $t_{B}$-voters vote sincerely with a probability of at least $17.56 \%$. We conducted sessions with these parameters only under runoff elections, because the comparable case under plurality is the baseline treatment. Beyond increasing the incentives to vote sincerely, this treatment allows us to explore the validity of our conjecture that some voters do not understand that the decision to vote for either $A$ or $B$ does not affect differentially the likelihood that $C$ wins in the first round outright. For rational voters, a key determinant of the decision to abandon one's preferred candidate is the risk of an upset victory in the second round. If some voters continue to vote always Duvergerian, it would suggest that they do not understand well the influence of their vote in the first round of a majority runoff election.

\subsection{Experimental Results}

Aggregate voting behavior. Voting behavior in the new treatments is summarized in

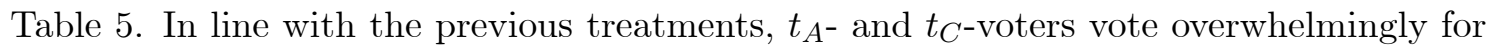
their preferred alternative, and therefore, we focus on the behavior of $t_{B}$-voters. 


\begin{tabular}{ccccccccc} 
& & \multicolumn{3}{c}{ Small Minority } & & \multicolumn{3}{c}{ No Upset } \\
\cline { 3 - 5 } \cline { 7 - 9 } & & $\% \mathrm{~A}$ & $\% \mathrm{~B}$ & $\% \mathrm{C}$ & & $\% \mathrm{~A}$ & $\% \mathrm{~B}$ & $\% \mathrm{C}$ \\
\hline \multirow{6}{*}{ Plurality } & $t_{A}$ & 96.59 & 1.59 & 1.81 & & - & - & - \\
& $t_{B}$ & 66.08 & 33.33 & 0.58 & & - & - & - \\
& $t_{C}$ & 3.00 & 0.66 & 96.34 & & - & - & - \\
\hline \multirow{6}{*}{ Runoff } & $t_{A}$ & 97.17 & 1.96 & 0.87 & & 92.34 & 5.58 & 2.08 \\
& $t_{B}$ & 43.02 & 54.19 & 2.79 & & 31.92 & 67.14 & 0.94 \\
& $t_{C}$ & 2.05 & 1.47 & 96.48 & & 2.13 & 1.35 & 96.52 \\
\hline
\end{tabular}

Table 5: Aggregate behavior in the additional treatments.

Do we observe a higher frequency of sincere voting under runoff in the SM treatments than in the baseline? Under R_SM, sincere voting equals $54.19 \%$, as opposed to $40.26 \%$ observed in the R_B treatment. However, Table 12 shows that this difference is not significant for the random effects model ( $\mathrm{p}$-value $=0.194$ in the model with controls, clustered at the group level). Hence, these results suggest that even if voters seem to react to the change in incentives implied by the reduction in the proportion of $t_{C}$-voters, insincere voting still equals almost $50 \%$ of decisions. Coordination forces remain strong, implying that the fraction of Duvergerian $t_{B}$-voters is non-negligible under this treatment and that the levels of sincere voting are still far away from full convergence to the sincere voting equilibrium. ${ }^{38}$

There is substantial heterogeneity across groups under R_SM: the percentages of sincere voting in the different groups were $15.25 \%, 50.64 \%, 56.15 \%, 68.51 \%$, and $82.39 \%$. As already mentionned, in this treatment, the minimal percentage of sincere voting by $t_{B}$-voters that makes sincere voting a best response is $47.87 \%$. Therefore, sincere voting is the best response in all but one of the groups. Nevertheless, the groups with high initial frequency of sincere voting do not display an increase in sincerity over time. The right-panel of Figure 9 shows, indeed, that groups either exhibit no temporal trend or a decreasing one.

The R_NU treatment, features even stronger incentives to vote sincerely: sincere voting is the best response as long as other $t_{B}$-voters vote sincerely with a probability of at least $17.56 \%$. And indeed, we observe a significantly higher amount of sincere voting

\footnotetext{
${ }^{38}$ In line with what we observed with the Baseline parameters, there is a signifficant difference of about 23 percentage points of sincere voting between runoff and plurality under the SM configuration ( $\mathrm{p}$-value $=0.028$, see Table 10 in the Appendix). Under SM plurality, we observe $33.33 \%$ of sincere voting as opposed to the $24.14 \%$ observed in the baseline. This difference is significant under a random effects model similar to that used previously ( $\mathrm{p}$-value $=0.034)$.
} 


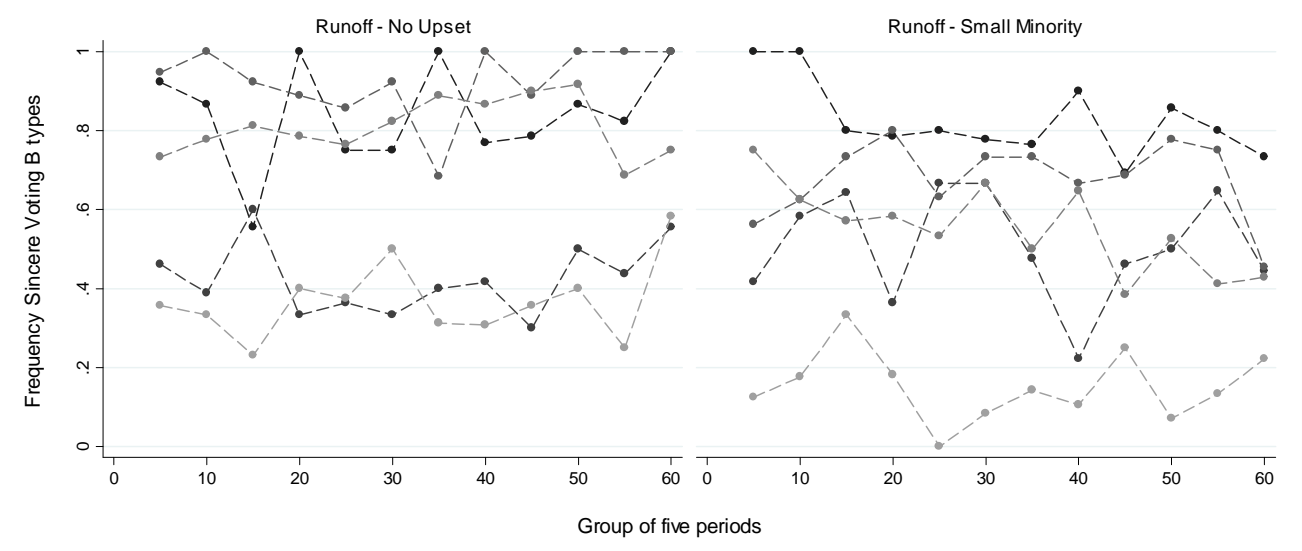

Figure 9: Temporal evolution of sincere voting by $t_{B}$-voters in $\mathrm{R}_{-} \mathrm{NU}$ and $\mathrm{R} \_\mathrm{SM}$ treatments.

than in all other runoff treatments: $67.14 \%$. Table 13 shows that using random effects regressions, and compared to the $\mathrm{R} \_\mathrm{B}$ treatment, $t_{B}$-voters are 28 percentage points more likely to vote sincerely $(\mathrm{p}$-value $=0.018) .{ }^{39}$ Consequently, when the threat of an upset victory of the minority candidate in the second round vanishes, sincere voting among $t_{B^{-}}$ voters is larger. Nonetheless, we find it striking that a non-negligible fraction of these voters continue to abandon their most-preferred candidate.

As with the other treatments, $\mathrm{R}_{-}$NU also displays some heterogeneity across groups, as shown in the left-panel of Figure 9. There are two sets of groups. One the one hand, three groups feature behavior in line with the sincere voting equilibrium. The frequency of sincere voting in these groups is over $80 \%$. On the other hand, two groups feature no convergence to either the sincere or to the Duverger's law equilibrium. In these groups, $t_{B}$-voters vote for $B$ around $40 \%$ of the time, which means that the best response to observed behavior is unambiguously to vote sincerely.

Individual Behavior. Figure 10 represents individual behavior of $t_{B}$-voters under the SM (plurality and runoff) and NU (runoff) configurations. Consistent with the results in the main treatments, there are two prominent clusters of voters: those who always vote sincerely and those who always vote Duvergerian. But the relative size of these two

\footnotetext{
${ }^{39}$ The difference is even larger when compared to the $\mathrm{R}_{-} \mathrm{LD}$ case: 39 percentage points ( $\mathrm{p}$-value $=0.000$ ). Additionally, taking $\mathrm{P}_{-} \mathrm{B}$ as the reference for plurality, Tāble 11 in the Appendix shows that the difference of about 49 percentage points of sincere voting between runoff and plurality is highly significant, in the random-effects model that includes subject-level covariates.
} 

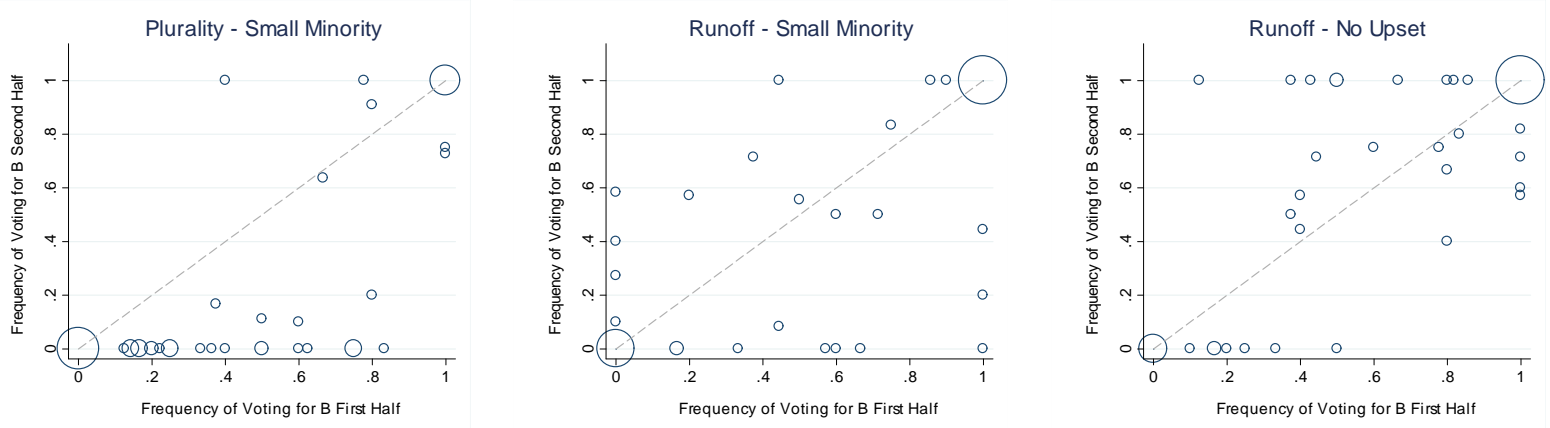

Figure 10: Individual behavior in the new treatments.

clusters varies across electoral rules. The percentage of always sincere voters is smaller under plurality than under both runoff treatments. In $\mathrm{P}_{-} \mathrm{SM}, 15 \%$ of voters always vote sincerely, while this percentage is $38 \%$ under both $\mathrm{R} \_\mathrm{SM}$ and $\mathrm{R} \_\mathrm{NU}$. There are also significantly more voters of this kind under these new runoff treatments, compared to R_B, where the proportion of always-sincere voters was just $8.3 \%$. The percentage of always Duvergerian voters are $28 \%, 23 \%$ and $13 \%$ in P_SM, R_SM and R_NU, respectively. This compares to $23.6 \%$ of always Duvergerian voters in the $\mathrm{R} \_\mathrm{B}$ treatment. We find it striking that $13 \%$ of voters always vote Duvergerian even if the risk of upset victory of $C$ in the second round is almost null. We interpret this result as suggestive evidence that a substantial fraction of voters misunderstand the influence of their ballot in the first round of a runoff election.

Differences in the numbers of always sincere and always Duvergerian voters explain heterogeneity in behavior across groups. As Figure 9 shows, in the NU treatment, there are two individual groups that clearly converged to the sincere voting equilibrium. The percentage of always Duvergerian voters in these two groups are $0 \%$ in both cases, while such proportions for the remaining three groups are $33.3 \%, 8.3 \%$, and $25 \%$ repectively. A similar pattern exists in SM treatments: groups that coordinate more behind one of the majority candidates are the ones with the largest proportions of always Duvergerian voters. The group exhibiting the highest frequency of sincere voting has $0 \%$ of always Duvergerian voters, the three intermediate groups have proportions of $33.3 \%, 8.3 \%$, and $8.3 \%$, while for the group with less sincere voting $58.3 \%$ of its $t_{B}$-voters are always Duvergerian.

After this analysis of individual behavior, the obvious next step is to understand why 


\begin{tabular}{|c|c|c|c|c|c|c|c|c|}
\hline & & & \multicolumn{3}{|c|}{ Small Minority } & \multicolumn{3}{|c|}{ No Upset } \\
\hline & & & $\% \mathrm{~A}$ & $\% \mathrm{~B}$ & $\% \mathrm{C}$ & $\% \mathrm{~A}$ & $\% \mathrm{~B}$ & $\% \mathrm{C}$ \\
\hline \multirow{4}{*}{ Plurality } & Realized & All periods & 76.23 & 0.32 & 23.46 & - & - & - \\
\hline & & Second Half & 78.70 & 0.04 & 21.26 & - & - & - \\
\hline & Theory & Duv. Eq. & 86.19 & 0.00 & 13.81 & - & - & - \\
\hline & & Sincere & 48.19 & 11.33 & 40.48 & - & - & - \\
\hline \multirow[t]{4}{*}{ Runoff } & Realized & All periods & 75.26 & 5.19 & 19.55 & 67.41 & 9.87 & 22.72 \\
\hline & & Second Half & 75.16 & 3.79 & 21.05 & 67.93 & 9.45 & 22.62 \\
\hline & Theory & Duv. Eq. & 82.80 & 0.00 & 17.21 & 77.68 & 0.00 & 22.32 \\
\hline & & Sincere & 61.96 & 16.52 & 21.52 & 59.34 & 16.16 & 24.50 \\
\hline
\end{tabular}

Table 6: Simulated outcomes in the new treatments. All periods uses the average frequencies for each while Second Half uses the averages only for the second half. The equilibrium benchmarks are based on the simulated data.

some voters always vote for $B$ (always sincere), while others always vote for $B$ (always Duvergerian), as we examined in behavior above. As in the main treatments, the only characteristic that appears to play a role is gender: female participants are less likely to be always Duvergerian and more likely to be always sincere. See Figure 14 (in Appendix A7).

Outcomes. We turn to the realized electoral outcomes for the SM and NU treatments. The change of behavior observed in these new treatments begs two important questions: (i) are there differences under runoff compared to the baseline treatment? and (ii) are there bigger institutional differences than the ones observed in section 6 ? Table 6 presents both the theoretically and the simulated probabilities of victory of the different alternatives based on individual average behavior for the new treatments. ${ }^{40}$ The analysis clearly suggests that the answer to both questions is positive. These answers make sense given the increase in sincere voting in the new treatment. But, are the differences statistically significant?

Let us first focus on the differences in outcomes under majority runoff rule across treatments. For this purpose, we compare the probability of victory of each alternative under the new treatments versus the baseline treatment. We estimate random effects regressions, where we regress the probability of victory of each candidate on a treatment indicator (Small Minority or No Upset), using the runoff baseline group as the benchmark.

\footnotetext{
${ }^{40}$ The simulations were produced exactly as in the previous section (see footnote 33 for details).
} 
The results of these regressions are reported in Table 15 in the Appendix. ${ }^{41}$ Columns 13 show that in the case of Small Minority, the reduction in the expected proportion of $t_{C}$-voters has a negative effect on the probability that $C$ wins the election. In fact, the reduction in this probability is about the same as the combined increase in the likelihood that either $A$ or $B$ wins the election (although the coefficients for these two outcomes, despite being positive, are not individually significant). For the No Upset treatment, there is a sharp and significant higher probability that $B$ wins the election (of about 12 percentage points), while the probability that $C$ wins diminishes in 6.6 percentage points. Alternative $A$ also exhibits a reduction in its probability of victory, albeit not statistically significant. Hence, making almost $100 \%$ likely a defeat of $C$ in the second round, notably increases the chances of victory of $B$.

Let us now analyze the differences in outcomes for the new runoff treatments compared to their plurality counterparts. For the Small Minority treatment, we compare R_SM with $\mathrm{P} \_\mathrm{SM}$, while in the case of No Upset, $\mathrm{R}_{-} \mathrm{NU}$ is compared against $\mathrm{P} \_\mathrm{B}$. As before, we estimate random effects models, where the probability of victory of each candidate is regressed on a treatment indicator. Table 16 in the Appendix reports the results of these regressions. Columns 1-3 show that under the Small Minority condition, the existence of runoff elections increases $B$ 's chances of victory in 4.3 percentage points (p-value $=0.074$ ), at the expense of $A$ and $C$. In the case of the No Upset treatment, columns 4-6 show that the increase in the probability that $B$ wins the election is even higher (13 percentage points and $\mathrm{p}$-value $=0.014)$ and is explained by a decrease in $C$ 's winning probability.

The benefits of better preference revelation and aggregation discussed previously bring a potential cost for voters: an increase in the likelihood of having a second round. Remember that the frequency of a second round in the $\mathrm{R}_{-} \mathrm{B}$ treatment was $47.78 \%$. Under R_SM, we observed only a marignal and not significant increase to $49.33 \%$ (p-value = 0.895). Under $R_{-}$NU, however, there was a significant increase to $62.00 \%$ (p-value $=$ 0.054). As Figure 11 shows, there is no strong temporal change over time. The figure also shows that, while under R_SM, the probability of a second round lies between the predictions of the sincere voting and Duverger's law equilibria, the frequency of a second round under $\mathrm{R}_{-} \mathrm{NU}$ is close to the prediction under the sincere voting equilibrium. These results

\footnotetext{
${ }^{41}$ Again, standard errors are clustered at the group level.
} 

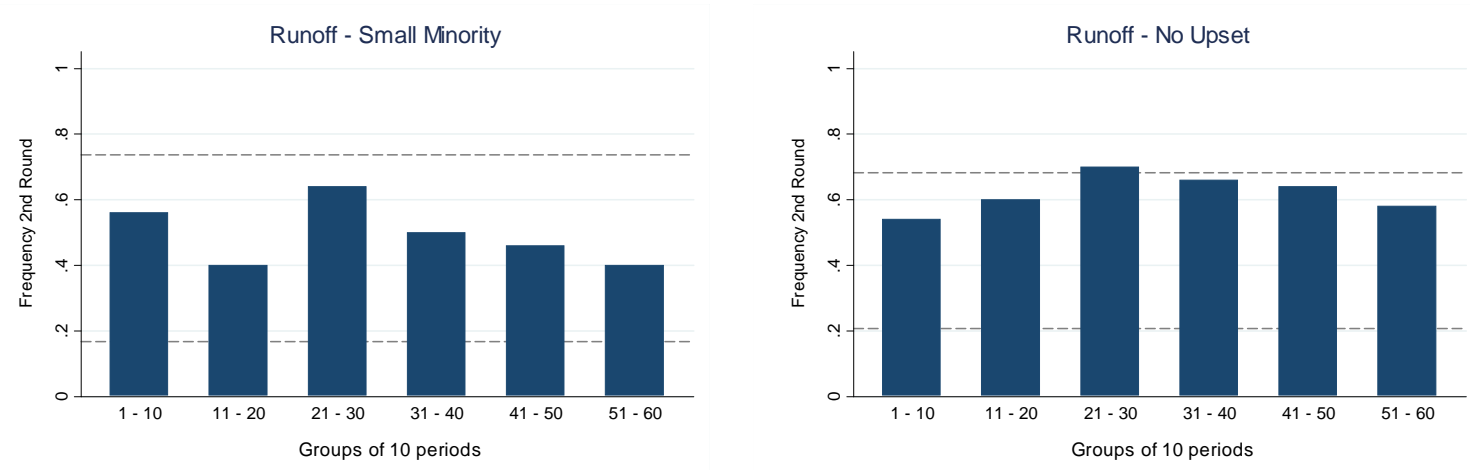

Figure 11: Probability of reaching the second round over time. The upper (lower) gray dashed line indicates the theoretical probability of reaching the second round in the sincere voting (Duverger's Law) equilibrium. Note that the theoretical predictions in $R_{S} M$ are the same that in $R_{B}$.

highlight that the trade-off between preference aggregation and cost of a second round that underlies the choice between plurality and runoff is indeed binding in the laboratory.

\section{Conclusion}

One of the believed advantages of runoff electoral systems is that, compared to plurality rule, they favor preference revelation by voters: Duvergerian incentives are supposedly weaker. Such preference revelation is seen as advantageous: it can lead to the selection of a better alternatives, and also inform both voters and candidates as to the distribution of preferences in the electorate.

However, theoretical analyses show that Duvergerian incentives also exist in runoff systems. Voters may vote strategically as they are predicted to do under plurality rule: some voters abandon their most preferred alternative when it is unlikely to be in contention for victory. In fact, under some conditions the only equilibria under runoff electoral systems involve such strategic behavior.

In this paper, we investigate the extent that voting is more sincere in runoff systems than it is in plurality elections using laboratory experiments, testing the theoretical predictions. We find that voters vote strategically in runoff elections in comparable numbers to the levels we observe in plurality rule elections. Moreover, the amount of strategic voting observed is in some cases above that predicted by theoretical analyses. Hence, we do not see strong evidence that runoff elections are effective in allowing voters to better reveal 
their preferences.

The comparable voting behavior under both plurality and runoff systems lead to small differences in terms of outcomes. But in contrast to plurality, even with the observed high levels of strategic voting, runoff elections required a second round in many instances. Given the substantial additional costs of running a second round, a simple benefit-cost analysis casts some doubts on the desirability of such voting system. 


\section{References}

[1] Acemoglu, D., 2005. Constitutions, politics, and economics: a review essay on Persson and Tabellini's The Economic Effects of Constitutions. Journal of Economic Literature, 43(4), pp.1025-1048.

[2] Ballard, M. 2016. In rarely seen twist, last-minute candidate Taylor Barras selected Louisiana House speaker. The Advocate, Jan. 14, 2016, https://www.theadvocate.com/baton_rouge/news/politics/legislature/article_1e1b57db13d3-5822-b86f-62ed800f1ce3.html, accessed May 19, 2019.

[3] Bendor, J., Diermeier, D., Siegel, D.A. and Ting, M.M., 2011. A behavioral theory of elections. Princeton University Press.

[4] Blais, A., 2004a. Strategic voting in the 2002 French presidential election. In The French Voter: Before and After the 2002 Election (pp. 93-109). Palgrave Macmillan, London.

[5] Blais, A., 2004b. Y a-t-il un vote stratégique en France?. In Le nouveau désordre électoral (pp. 279-301). Presses de Sciences Po (PFNSP).

[6] Bordignon, M., Nannicini, T. and Tabellini, G., 2016. Moderating political extremism: single round versus runoff elections under plurality rule. American Economic Review, 106(8), pp.2349-70.

[7] Bormann, N.-C., and M. Golder. 2013. Democratic Electoral Systems Around the World, 1946-2011. Electoral Studies, 32: 360-369.

[8] Bouton, L., 2013. A theory of strategic voting in runoff elections. American Economic Review, 103(4), pp.1248-88.

[9] Bouton, L., and M. Castanheira (2012). One Person, Many Votes: Divided Majority and Information Aggregation. Econometrica, 80(1), 43-87.

[10] Bouton, L., Castanheira, M. and Llorente-Saguer, A., 2016. Divided majority and information aggregation: Theory and experiment. Journal of Public Economics, 134, pp.114-128. 
[11] Bouton, L., Castanheira, M. and Llorente-Saguer, A., 2017. Multicandidate elections: Aggregate uncertainty in the laboratory. Games and Economic Behavior, 101, pp.132150.

[12] Bouton, L. and Gratton, G., 2015. Majority runoff elections: strategic voting and Duverger's hypothesis. Theoretical Economics, 10(2), pp.283-314.

[13] Bouton, L. and Ogden, B.G., 2017. Group-based Voting in Multicandidate Elections. National Bureau of Economic Research, No. w23898.

[14] Callander, S. (2005). Duverger's Hypothesis, the Run-Off Rule, and Electoral Competition. Political Analysis, 13, pp. 209-232.

[15] Castanheira, M. (2003). Why Vote for Losers?, Journal of the European Economic Association, 1, pp. 1207-1238.

[16] Colomer, Josep M., 2007. On the origins of electoral systems and political parties: the role of elections in multi-member districts. Electoral Studies, 26, pp. 262-273.

[17] Cox, G.W., 1997. Making votes count: strategic coordination in the world's electoral systems. Cambridge University Press.

[18] Dewan, T. and Myatt, D. (2007). Leading the Party: Coordination, Direction, and Communication. American Political Science Review, 101 (4), pp. 825-843.

[19] Duverger, M., 1959. Political parties: Their organization and activity in the modern state. Methuen.

[20] Engstrom, R.L. and Engstrom, R.N., 2008. The majority vote rule and runoff primaries in the United States. Electoral Studies, 27(3), pp.407-416.

[21] Fey, M., 1997. Stability and coordination in Duverger's law: A formal model of preelection polls and strategic voting. American Political Science Review, 91(1), pp.135147.

[22] Fischbacher, U., 2007. z-Tree: Zurich toolbox for ready-made economic experiments. Experimental economics, 10(2), pp.171-178. 
[23] Forsythe, R., Myerson, R.B., Rietz, T.A. and Weber, R.J., 1993. An experiment on coordination in multi-candidate elections: The importance of polls and election histories. Social Choice and Welfare, 10(3), pp.223-247.

[24] Forsythe, R., Rietz, T., Myerson, R. and Weber, R., 1996. An experimental study of voting rules and polls in three-candidate elections. International Journal of Game Theory, 25(3), pp.355-383.

[25] Fujiwara, T., 2011. A regression discontinuity test of strategic voting and Duverger's Law. Quarterly Journal of Political Science, 6(3-4), pp.197-233.

[26] Golder, M., 2006. Presidential coattails and legislative fragmentation. American Journal of Political Science, 50(1), pp.34-48.

[27] Lizzeri, A., and N. Persico 2005. The Drawbacks of Electoral Competition, Journal of the European Economic Association, 3(6), pp. 1318-1348.

[28] Martinelli, C., 2002. Simple plurality versus plurality runoff with privately informed voters. Social Choice and Welfare, 19(4), pp.901-919.

[29] McClintock, C., 2018. Electoral Rules and Democracy in Latin America, Oxford: Oxford University Press.

[30] Morton, R.B. and Rietz, T.A., 2007. Majority requirements and minority representation. New York University Annual Survey of American Law,,63, p.691.

[31] Myatt, D.P., 2007. On the theory of strategic voting. The Review of Economic Studies, 74(1), pp.255-281.

[32] Myerson, R. (2002). Comparison of Scoring Rules in Poisson Voting Games. Journal of Economic Theory, 103, pp. 219-251.

[33] Myerson, R. and Weber, R. (1993). A Theory of Voting Equilibria. American Political Science Review, 87, pp. 102-114.

[34] Osborne, M. and Slivinski, A. (1996). A Model of Political Competition with CitizenCandidates. Quarterly Journal of Economics, 111, pp. 65-96. 
[35] Palfrey, T.R., 1984. Spatial Equilibrium with Entry. Review of Economic Studies, 51(1), pp. 139-156.

[36] Palfrey, T.R., 1989. A Mathematical Proof of Duverger's Law. In Models of Strategic Choice in Politics, ed. Peter C. Ordeshook. Ann Arbor: University of Michigan Press.

[37] Perez-Linan, A., 2006. Evaluating Presidential Runoff Elections. Electoral Studies, 25, pp. 129-146.

[38] Piketty, T., 2000. Voting as communicating. The Review of Economic Studies, 67(1), pp.169-191.

[39] Riker, W.H., 1982. The two-party system and Duverger's law: an essay on the history of political science. American Political Science Review, 76(4), pp.753-766.

[40] Saari, D.G., 2003. Unsettling aspects of voting theory. Economic Theory, 22(3), pp.529-555.

[41] Schuessler, A.A., 2000. A logic of expressive choice. Princeton University Press.

[42] Shugart, M.S. and Taagepera, R., 1994. Plurality versus majority election of presidents: A proposal for a "double complement rule". Comparative Political Studies, 27(3), pp.323-348.

[43] Smith, J.H., 1973. Aggregation of preferences with variable electorate. Econometrica, pp.1027-1041.

[44] Solow, B., 2019. Aggregate Uncertainty in Runoff Elections. mimeo.

[45] Stewart, Charles III and Stephen Ansolabehere, 2015. Waiting to vote. Election Law Journal, 14(1):47-53.

[46] Van der Straeten, K., Laslier, J.F., Sauger, N. and Blais, A., 2010. Strategic, sincere, and heuristic voting under four election rules: an experimental study. Social Choice and Welfare, 35(3), pp.435-472.

[47] Van der Straeten, K., Laslier, J.F. and Blais, A., 2016. Patterns of strategic voting in run-off elections. In Voting Experiments (pp. 215-236). Springer, Cham. 
[48] Wright, S.G. and Riker, W.H., 1989. Plurality and runoff systems and numbers of candidates. Public Choice, 60(2), pp.155-175. 


\section{Appendix}

\section{A1. Proofs of Section 4}

Proof of Proposition 1. Part (i): direct from Proposition 2 in Bouton, Castanheira, and Llorente-Saguer (2017).

Part (ii): Let us consider the case with an even number of voters (the proof is similar for an odd number of voters). We prove that $\sigma_{t}^{R}(A)=1 \forall t \in\left\{t_{A}, t_{B}\right\}$ is an equilibrium. In that case, the only possible pivotal events under runoff (i.e., the only ones that are not zero probability events) are the threshold pivotability $A / A C$ and $C / A C$. Indeed, when all majority voters are voting for $A$, and minority voters are voting for $C$, either one alternative obtains strictly more than $\frac{n}{2}$ with a lead of two votes or more, or the two alternatives tie. Thus, from the standpoint of a given voter, the only situation in which a ballot can change the final outcome is when either $A$ is lacking one vote to win outright or $C$ does. Majority voters of both types thus strictly prefer voting for $A$ because that eliminates the risk of an upset victory of $C$ in the second round.

\section{A2. Large Electorate}

In this Appendix, we analyze the strategic behavior of voters under plurality and majority runoff when the electorate grows large. ${ }^{42}$ The advantage of focusing on large electorate is that it greatly facilitates the equilibrium analysis, and allows for general results. This explains why this approach is widespread in the literature, The main drawback for our purpose is that we cannot reproduce such a large electorate in the laboratory. This is why we analyzed the behavior of voters under both plurality and runoff when the electorate is small in Section 4 .

Working under the assumption of a fixed number of voters does not prevent us from relying on the results in Bouton (2013) and Bouton and Gratton (2015), or in other papers assuming a Poisson distribution. As argued in Bouton (2013) and Bouton and Gratton (2015), large electorate results under a Poisson distribution of voters readily extend to the case of an electorate of fixed size. ${ }^{43}$

\footnotetext{
${ }^{42}$ This Appendix borrows heavily from Bouton (2013), Bouton and Gratton (2015), and Bouton, Castanheira, and Llorente-Saguer (2016).

${ }^{43}$ As explained in Bouton and Gratton (2015, p. 287): "Myerson (2000, p. 24) shows that, for large $n$, in a setup with a fixed number of voters whose preferences follow a multinomial distribution, pivot probabilities are a monotonic transformation of their Poisson equivalent. In other words, the magnitude ratios for multinomial distributions behave similarly as under Poisson distributions." As a consequence,
} 


\section{Plurality}

In large electorate, we can fully characterize the set of pure strategy equilibria under plurality:

Proposition 2 Under plurality:

(i) the two Duverger's Law equilibria always exist;

(ii) the sincere voting equilibrium exists if and only if $r\left(t_{A}\right)=r\left(t_{B}\right)$.

Proof of Proposition 2. Part (i): special case of Proposition 1 in Myerson (2002).

Part (ii): the proof of the necessary condition follows exactly the argument in the the proof of part (i). The proof of the sufficient condition follows directly from noticing that $\delta\left(n, n_{C}\right) \rightarrow_{n \rightarrow \infty} 0$ in Proposition 2 in Bouton, Castanheira, and Llorente-Saguer (2017).

The intuition for the existence of the Duverger's Law equilibria is as follows. When a majority alternative's expected vote share is too low, the probability of being pivotal for that alternative becomes extremely small. To avoid wasting their ballot, supporters of that alternative prefer to vote for the other majority alternative.

Now, the intuition for the condition necessary for the existence of the sincere voting becomes obvious. Majority voters do not want to coordinate behind the strongest majority alternative only if both alternatives have the same expected support in the electorate. Obviously, this is a very demanding condition: the sincere voting equilibrium is knife-edge (see, e.g., Palfrey 1989, Myerson and Weber 1993, and Fey 1997). ${ }^{44}$

\section{Majority Runoff}

The following proposition shows that Duverger's Law forces also exist under majority runoff:

Proposition 3 Under majority runoff, in the first round, the two Duverger's Law equilibria always exist.

their characterization of equilibria for large electorates extend to a setup with a fixed number of voters whose preferences follow a multinomial distribution, which is what we assume in this paper.

${ }^{44} \mathrm{An}$ implicit assumption of our setting is the absence of aggregate uncertainty. The result on the Duverger's equilibrium holds with and without aggregate uncertainty, except for extremely high level of aggregate uncertainty. However, with aggregate uncertainty, the sincere voting equilibrium exists for a broader set of distributions (see Myatt 2007 and Bouton, Castanheira, and Llorente-Saguer 2017). 
Proof of Proposition 3. Special case of Proposition 1 in Bouton and Gratton (2015).

The intuition behind this result is as follows. Consider a voter that expects two alternatives to receive (almost) all the votes, say $A$ and $C$. As the expected number of voters grows large, his vote can only be decisive in determining which of these two candidates will be elected outright in the first round (the magnitudes of two of the threshold pivotal events, $p i v_{A / A C}$ and $p i v_{C / C A}$, are larger than the magnitudes of any other event). That is because, if only two alternatives receive any vote, then one of them must receive a majority of the votes, except when candidates split the votes equally.

Even if they exist in the first round of a majority runoff election, Duverger's Law forces are weaker than under plurality. As a consequence, there are more situations in which all voters feel free to express their preferences and vote for their most-preferred candidate than under plurality. But, Duverger's law forces are still sufficiently strong to prevent the existence of the sincere voting equilibrium in some situations: ${ }^{45}$

Proposition 4 Under majority runoff, in the first round, there are $\varepsilon_{1}, \varepsilon_{2}>0$ such that:

(i) the sincere voting equilibrium exists if $r\left(t_{A}\right)-r\left(t_{B}\right) \leq \varepsilon_{1}, r\left(t_{A}\right)<r\left(t_{C}\right)$;

(ii) the sincere voting equilibrium does not exist if $r\left(t_{B}\right)<\varepsilon_{2}$

Proof of Proposition 4. Direct from the proof of Theorem 2 in Bouton (2013).

The intuition for the existence of the sincere voting equilibrium is as follows. Conditional on being pivotal, majority voters choose which majority alternative participates in the second round with $C$. The second-rank pivotability $C A / C B$ is most likely when $A$ and $B$ are, in expectations, relatively close to tying for second place (i.e., there is substantial disagreement among majority voters) and $C$ is expected not to pass the threshold (i.e., the minority is not too large). Since the probability of defeating $C$ in the second round is the same for both majority alternatives, majority voters vote for their most preferred alternative: $t_{A}$-voters vote $A$ and $t_{B}$-voters vote $B$.

Conversely, Proposition 4 also identifies when Duverger's law forces prevent the existence of the sincere voting equilibrium. There are situations in which some majority voters prefer to vote for their second-best alternative in the first round in order to avoid

\footnotetext{
${ }^{45}$ Bouton and Gratton (2015) show that the sincere voting equilibrium does not exist when the set of voter types is sufficiently rich. However, they also show the existence of a Duverger's hypothesis equilibrium in which more than two alternatives are expected to receive a positive vote share. In that equilibrium, only one type of voters does not vote for their most-preferred alternative.
} 
the risk of an upset victory in the second round (i.e. they are threshold pivotal in favor of a majority alternative). This happens when there is little disagreement among majority voters: one majority alternative has (many) more supporters than the other. Then, conditional on being pivotal, the election essentially boils down to a contest between one of the majority alternatives and $C$. Supporters of the weak majority alternative then prefer to abandon their most-preferred alternative in order to ensure an outright victory of the other majority alternative in the first round. 


\section{A3. Questionnaire Data}

In this section we describe the data collected in the questionnaire at the end of the experiment. Variables Party and Religion were not included in the regressions in Appendix A4 since there was no obvious way to aggregate them.

\begin{tabular}{|c|c|}
\hline Variable & Description \\
\hline Gender & Female $=1 ;$ Male $=0$ \\
\hline Age & Age in years. \\
\hline Year & Years of studies. \\
\hline Risk & Tendency to take risks. Likert scalefrom 1 to 5 . \\
\hline Trust & Tendency to trust people. Likert scale from 1 to 5 . \\
\hline Experiments & $\begin{array}{l}=1 \text { if the subject has participated in } 4 \text { or more experiments. Origi- } \\
\text { nally, this was a categorical variable about participation in previous } \\
\text { experiments: "Never", "1-3", " } 4-6 " \text {, and "More than } 6 " .\end{array}$ \\
\hline Politics & $\begin{array}{l}=1 \text { if politics is very important or extremely important in the } \\
\text { subject's life. Originally Likert scale from } 1 \text { to } 4 \text {. }\end{array}$ \\
\hline Religiosity & $\begin{array}{l}\text { Degree of religiosity. Likert scale from } 1 \text { to } 4 \text {. Not included in } \\
\text { the regressions. }\end{array}$ \\
\hline Religion & $\begin{array}{l}\text { Categorical variable: Christian }(22.69 \%) \text {, Hinduist }(41.44 \%) \text {, } \\
\text { Judaism }(2.55 \%) \text {, Muslim }(4.17 \%) \text {, No religion }(18.98 \%) \text {, Other } \\
\text { Religion }(5.79 \%) \text {, Prefer not to answer }(4.40 \%) \text {. Not included in the } \\
\text { regressions. }\end{array}$ \\
\hline Major & $\begin{array}{l}\text { Categorical variable with the options: } \\
\text { "Law" }(0.93 \%), \text { "Economics" }(12.96 \%), \\
\text { "Literature" (0.69\%), "Physics/Chemistry/Biology" }(5.79 \%), \\
\text { "Engineering" ( } 37.50 \%) \text {, "History" }(0.93 \%) \text {, "Politics" }(3.01 \%) \text {, } \\
\text { "Mathematics" (0.28\%), "Others" (34.49\%). } \\
\text { Not included in the regressions. }\end{array}$ \\
\hline Party & $\begin{array}{l}\text { Categorical variable: Democrat }(43.75 \%) \text {, Republican }(7.18 \%) \text {, } \\
\text { Other }(10.65 \%) \text {, NA }(38.43 \%) \text {. Not included in the regressions. }\end{array}$ \\
\hline Siblings & Number of siblings. Not included in the regressions. \\
\hline
\end{tabular}

Table 7: Description of variables in the questionnaire data. 


\section{A4. Regression Analysis}

This section presents the basic regression analysis of the experiment. For this purpose, a panel dataset at the subject/period level was constructed. Random effects regression models are estimated for B voters and the outcome of interest is whether the subject votes sincerely or not (i.e. votes for candidate B). In every case, standard errors are clustered at the group level. Throughout Tables 8-11, we compare the effect of having the runoff rule on the probability of voting sincerely. Table 8 compares runoff and plurality under the baseline configuration; Table 9 corresponds to the low disagreement case; Table 10 does the same but under the small minority configuration; while Table 11 compares runoff and plurality under the No Upset rule.

For each treatment configuration, six different models are estimated. In each table, column 1 corresponds to a model in which we do not control for subject-level covariates. Column 2 corresponds to models with covariates, which include subjects' gender, age, years in school, level of risk, level of trust, and dummies for experience participating in experiments and interest in politics. Column 3 includes a dummy indicating whether the minority candidate $(\mathrm{C})$ won the previous election or not. Column 4 includes a count variable indicating the number of elections previously won by the minority candidate. Column 5 includes the interaction between the runoff condition and the indicator of whether $\mathrm{C}$ won the previous election, to test for heterogeneous effects at such level. Column 6 does the same, but for the the number of previous elections won by $\mathrm{C}$.

Tables 12 and 13 compare the different runoff configurations. On Table 12 we compare the basic runoff treatments across each other. Columns 1 and 2 compare the small minority and baseline conditions; columns 3 and 4 the low disagreement and baseline treatments; while columns 5 and 6 compare our small minority and low disagreement configurations. Table 13, on the other hand, compares each of these treatments with the new configuration, the No Upset configuration. Finally, Tables 14-16 compare the election outcomes across the different treatment configurations. 
Table 8: Runoff Elections and B-Voters' Sincerity under Baseline

\begin{tabular}{|c|c|c|c|c|c|c|}
\hline & $\begin{array}{c}(1) \\
\text { Vote B }\end{array}$ & $\begin{array}{c}(2) \\
\text { Vote B }\end{array}$ & $\begin{array}{c}(3) \\
\text { Vote B }\end{array}$ & $\begin{array}{c}(4) \\
\text { Vote B }\end{array}$ & $\begin{array}{c}(5) \\
\text { Vote B }\end{array}$ & $\begin{array}{c}(6) \\
\text { Vote B }\end{array}$ \\
\hline Runoff & $\begin{array}{c}0.164^{*} \\
(0.0964)\end{array}$ & $\begin{array}{c}0.180^{* *} \\
(0.0890)\end{array}$ & $\begin{array}{c}0.180^{* *} \\
(0.0891)\end{array}$ & $\begin{array}{c}0.152^{*} \\
(0.0900)\end{array}$ & $\begin{array}{c}0.168^{*} \\
(0.0872)\end{array}$ & $\begin{array}{c}0.209^{* *} \\
(0.0905)\end{array}$ \\
\hline Lag C Victory & & & $\begin{array}{c}-0.00526 \\
(0.0210)\end{array}$ & & $\begin{array}{l}-0.0288 \\
(0.0201)\end{array}$ & \\
\hline No. of C Victories & & & & $\begin{array}{c}-0.0174^{* * *} \\
(0.00288)\end{array}$ & & $\begin{array}{r}-0.0145^{* * *} \\
(0.00376)\end{array}$ \\
\hline Runoff $\times$ Lag C Victory & & & & & $\begin{array}{c}0.0435 \\
(0.0385)\end{array}$ & \\
\hline Runoff $\times$ No. of C Victories & & & & & & $\begin{array}{c}-0.00635 \\
(0.00505)\end{array}$ \\
\hline Constant & $\begin{array}{l}0.239^{* * *} \\
(0.0700)\end{array}$ & $\begin{array}{l}-0.419 \\
(0.337)\end{array}$ & $\begin{array}{l}-0.418 \\
(0.337)\end{array}$ & $\begin{array}{l}-0.221 \\
(0.354)\end{array}$ & $\begin{array}{l}-0.412 \\
(0.339)\end{array}$ & $\begin{array}{l}-0.242 \\
(0.363)\end{array}$ \\
\hline Subject-level Covariates & $\mathrm{N}$ & $\mathrm{Y}$ & $\mathrm{Y}$ & $\mathrm{Y}$ & $\mathrm{Y}$ & $\mathrm{Y}$ \\
\hline$N$ & 1798 & 1798 & 1798 & 1798 & 1798 & 1798 \\
\hline $\begin{array}{l}\text { Notes: Standard errors clustered } \\
B \text { or not. Runoff indicates whe } \\
\text { won the previous election. No. } \\
\text { include: gender, age, years in sc } \\
\text { experiments and interest in poli } \\
\text { sionificant at the } 1 \% \text { level. }\end{array}$ & $\begin{array}{l}\text { group lev } \\
\text { er the trea } \\
C \text { Victori } \\
\text { ol, level c } \\
\text { s. * is si }\end{array}$ & $\begin{array}{l}\text { iparenthe } \\
\text { ent corres } \\
\text { s the num } \\
\text { isk, level } \\
\text { icant at t }\end{array}$ & $\begin{array}{l}\text { Vote } B \\
\text { nds to } R \\
\text { r of previo } \\
\text { trust, and } \\
10 \% \text { level }\end{array}$ & $\begin{array}{l}\text { licates if the } \\
\text { or } P_{-} B \text {. } L \\
\text { victories of } \\
\text { ummies for } \\
* \text { is signific }\end{array}$ & $\begin{array}{l}\text { bject votes } \\
C \text { Victory } \\
\text { Subject-le } \\
\text { perience pa } \\
t \text { at the } 5 \%\end{array}$ & $\begin{array}{l}\text { or candidate } \\
\text { ndicates if } C \\
\text { el covariates } \\
\text { ticipating in } \\
\text { level, } * * * \text { is }\end{array}$ \\
\hline
\end{tabular}


Table 9: Runoff Elections and B-Voters' Sincerity under Low Disagreement

\begin{tabular}{|c|c|c|c|c|c|c|}
\hline & $\begin{array}{c}(1) \\
\text { Vote B }\end{array}$ & $\begin{array}{c}(2) \\
\text { Vote B }\end{array}$ & $\begin{array}{c}(3) \\
\text { Vote B }\end{array}$ & $\begin{array}{c}(4) \\
\text { Vote B }\end{array}$ & $\begin{array}{c}(5) \\
\text { Vote B }\end{array}$ & $\begin{array}{c}(6) \\
\text { Vote B }\end{array}$ \\
\hline Runoff & $\begin{array}{c}-0.00597 \\
(0.0568)\end{array}$ & $\begin{array}{c}0.0174 \\
(0.0497)\end{array}$ & $\begin{array}{c}0.0173 \\
(0.0502)\end{array}$ & $\begin{array}{c}0.0360 \\
(0.0544)\end{array}$ & $\begin{array}{c}0.0492 \\
(0.0564)\end{array}$ & $\begin{array}{c}0.0217 \\
(0.0608)\end{array}$ \\
\hline Lag C Victory & & & $\begin{array}{c}0.000705 \\
(0.0312)\end{array}$ & & $\begin{array}{c}0.0596^{* * *} \\
(0.0171)\end{array}$ & \\
\hline No. of C Victories & & & & $\begin{array}{c}-0.0152^{* * *} \\
(0.00150)\end{array}$ & & $\begin{array}{c}-0.0161^{* * *} \\
(0.00233)\end{array}$ \\
\hline Runoff $\times$ Lag C Victory & & & & & $\begin{array}{c}-0.117^{* *} \\
(0.0481)\end{array}$ & \\
\hline Runoff $\times$ No. of C Victories & & & & & & $\begin{array}{c}0.00173 \\
(0.00290)\end{array}$ \\
\hline Constant & $\begin{array}{l}0.293^{* * *} \\
(0.0317)\end{array}$ & $\begin{array}{c}-0.562^{* *} \\
(0.256)\end{array}$ & $\begin{array}{c}-0.562^{* *} \\
(0.256)\end{array}$ & $\begin{array}{c}-0.510^{* *} \\
(0.257)\end{array}$ & $\begin{array}{c}-0.568^{* *} \\
(0.259)\end{array}$ & $\begin{array}{l}-0.505^{*} \\
(0.258)\end{array}$ \\
\hline Subject-level Covariates & $\mathrm{N}$ & $\mathrm{Y}$ & $\mathrm{Y}$ & $\mathrm{Y}$ & $\mathrm{Y}$ & $\mathrm{Y}$ \\
\hline$N$ & 977 & 977 & 977 & 977 & 977 & 977 \\
\hline $\begin{array}{l}\text { Notes: Standard errors clustered } \\
B \text { or not. Runoff indicates whe } \\
C \text { won the previous election. No. } \\
\text { include: gender, age, years in sc } \\
\text { experiments and interest in poli } \\
\text { sionificant at the } 1 \% \text { level. }\end{array}$ & $\begin{array}{l}\text { group lev } \\
\text { r the trea } \\
C \text { Victo } \\
\text { ol, level } \\
\text { s. * is si }\end{array}$ & $\begin{array}{l}\text { parenth } \\
\text { nt corres } \\
\text { is the nu } \\
\text { sk, level } \\
\text { cant at }\end{array}$ & $\begin{array}{l}\text { Vote } B \\
\text { ids to } R \\
\text { er of previ } \\
\text { rust, and }\end{array}$ & $\begin{array}{l}\text { cates if the } \\
\text { or } P_{-} L D \text {. } \\
\text { victories of } \\
\text { nmies for }\end{array}$ & $\begin{array}{l}\text { ject votes } \\
g C \text { Victor } \\
\text { Subject-ler } \\
\text { erience par } \\
\text { at the } 5 \%\end{array}$ & $\begin{array}{l}\text { candidate } \\
\text { indicates if } \\
\text { covariates } \\
\text { cipating in } \\
\text { vel, } * * * \text { is }\end{array}$ \\
\hline
\end{tabular}


Table 10: Runoff Elections and B-Voters' Sincerity under Small Minority

\begin{tabular}{|c|c|c|c|c|c|c|}
\hline & $\begin{array}{c}(1) \\
\text { Vote B }\end{array}$ & $\begin{array}{c}(2) \\
\text { Vote B }\end{array}$ & $\begin{array}{c}(3) \\
\text { Vote B }\end{array}$ & $\begin{array}{c}(4) \\
\text { Vote B }\end{array}$ & $\begin{array}{c}(5) \\
\text { Vote B }\end{array}$ & $\begin{array}{c}(6) \\
\text { Vote B }\end{array}$ \\
\hline Runoff & $\begin{array}{c}0.226^{*} \\
(0.128)\end{array}$ & $\begin{array}{l}0.231^{* *} \\
(0.105)\end{array}$ & $\begin{array}{l}0.232^{* *} \\
(0.105)\end{array}$ & $\begin{array}{l}0.202^{*} \\
(0.106)\end{array}$ & $\begin{array}{l}0.231^{* *} \\
(0.109)\end{array}$ & $\begin{array}{l}0.0876 \\
(0.102)\end{array}$ \\
\hline Lag C Victory & & & $\begin{array}{c}0.0270 \\
(0.0278)\end{array}$ & & $\begin{array}{c}0.0251 \\
(0.0492)\end{array}$ & \\
\hline No. of C Victories & & & & $\begin{array}{c}-0.0160^{* * *} \\
(0.00522)\end{array}$ & & $\begin{array}{c}-0.0251^{* * *} \\
(0.00593)\end{array}$ \\
\hline Runoff $\times$ Lag C Victory & & & & & $\begin{array}{c}0.00398 \\
(0.0536)\end{array}$ & \\
\hline Runoff $\times$ No. of C Victories & & & & & & $\begin{array}{c}0.0192^{* *} \\
(0.00805)\end{array}$ \\
\hline Constant & $\begin{array}{l}0.325^{* * *} \\
(0.0769)\end{array}$ & $\begin{array}{c}-1.145^{* * *} \\
(0.186)\end{array}$ & $\begin{array}{c}-1.146^{* * *} \\
(0.186)\end{array}$ & $\begin{array}{c}-1.068^{* * *} \\
(0.186)\end{array}$ & $\begin{array}{c}-1.146^{* * *} \\
(0.186)\end{array}$ & $\begin{array}{c}-0.995^{* * *} \\
(0.181)\end{array}$ \\
\hline Subject-level Covariates & $\mathrm{N}$ & $\mathrm{Y}$ & $\mathrm{Y}$ & $\mathrm{Y}$ & $\mathrm{Y}$ & $\mathrm{Y}$ \\
\hline$N$ & 1715 & 1715 & 1715 & 1715 & 1715 & 1715 \\
\hline $\begin{array}{l}\text { Notes: Standard errors clustered } \\
B \text { or not. Runoff indicates whe } \\
C \text { won the previous election. No. } \\
\text { include: gender, age, years in sc } \\
\text { experiments and interest in poli } \\
\text { sionificant at the } 1 \% \text { level. }\end{array}$ & $\begin{array}{l}\text { group lev } \\
\text { r the trea } \\
C \text { Victor } \\
\text { ol, level } \\
\text { s. } * \text { is si }\end{array}$ & $\begin{array}{l}\text { parenthe } \\
\text { nt corresp } \\
\text { is the nun } \\
\text { sk, level } \\
\text { cant at t }\end{array}$ & $\begin{array}{l}\text { Vote } B \text { i } \\
\text { ls to } R \_S \\
\text { r of previo } \\
\text { rust, and }\end{array}$ & $\begin{array}{l}\text { cates if the s } \\
\text { or } P \_S M \text {. } \\
\text { victories of } \\
\text { nmies for e } \\
\text { is significa }\end{array}$ & $\begin{array}{l}\text { ject votes } \\
g C \text { Victor } \\
\text { Subject-ler } \\
\text { erience par }\end{array}$ & $\begin{array}{l}\text { candidate } \\
\text { indicates if } \\
\text { covariates } \\
\text { cipating in } \\
\text { vel, } * * * \text { is }\end{array}$ \\
\hline
\end{tabular}


Table 11: Runoff Elections and B-Voters' Sincerity under No Upset

\begin{tabular}{lcccccc}
\hline \hline & $(1)$ & $(2)$ & $(3)$ & $(4)$ & $(5)$ & $(6)$ \\
& Vote B & Vote B & Vote B & Vote B & Vote B & Vote B \\
\hline Runoff & $0.423^{* * *}$ & $0.485^{* * *}$ & $0.486^{* * *}$ & $0.448^{* * *}$ & $0.468^{* * *}$ & $0.352^{* * *}$ \\
& $(0.131)$ & $(0.0941)$ & $(0.0933)$ & $(0.0942)$ & $(0.0977)$ & $(0.103)$ \\
Lag C Victory & & & 0.00363 & & -0.0286 & \\
& & & $(0.0198)$ & & $(0.0203)$ & \\
No. of C Victories & & & & $-0.0109^{* * *}$ & & $-0.0146^{* * *}$ \\
& & & & $(0.00324)$ & & $(0.00378)$ \\
Runoff×Lag C Victory & & & & & $0.0712^{* *}$ & \\
& & & & & $(0.0329)$ & \\
Runoff×No. of C Victories & & & & & & $0.0132^{* *}$ \\
Constant & & & & & & $(0.00554)$ \\
& $0.239^{* * *}$ & -0.0885 & -0.0893 & 0.0352 & -0.0829 & 0.0529 \\
Subject-level Covariates & $(0.0703)$ & $(0.355)$ & $(0.355)$ & $(0.375)$ & $(0.356)$ & $(0.376)$ \\
$N$ & $\mathrm{~N}$ & $\mathrm{Y}$ & $\mathrm{Y}$ & $\mathrm{Y}$ & $\mathrm{Y}$ & $\mathrm{Y}$ \\
\hline \hline
\end{tabular}

Notes: Standard errors clustered at group level in parentheses. Vote $B$ indicates if the subject votes for candidate $B$ or not. Runoff indicates whether the treatment corresponds to $R_{-} N U$ or $P \_B$. Lag C Victory indicates if $C$ won the previous election. No. of $C$ Victories is the number of previous victories of $C$. Subject-level covariates include: gender, age, years in school, level of risk, level of trust, and dummies for experience participating in experiments and interest in politics. ${ }^{*}$ is significant at the $10 \%$ level, ${ }^{* *}$ is significant at the $5 \%$ level, ${ }^{* * *}$ is significant at the $1 \%$ level.

Table 12: Comparison of Runoff Treatments

\begin{tabular}{|c|c|c|c|c|c|c|}
\hline & $\begin{array}{c}(1) \\
\text { Vote B }\end{array}$ & $\begin{array}{c}(2) \\
\text { Vote B }\end{array}$ & $\begin{array}{c}(3) \\
\text { Vote B }\end{array}$ & $\begin{array}{c}(4) \\
\text { Vote B }\end{array}$ & $\begin{array}{c}(5) \\
\text { Vote B }\end{array}$ & $\begin{array}{c}(6) \\
\text { Vote B }\end{array}$ \\
\hline Small Minority & $\begin{array}{c}0.148 \\
(0.121)\end{array}$ & $\begin{array}{c}0.140 \\
(0.108)\end{array}$ & & & $\begin{array}{l}0.264^{* *} \\
(0.112)\end{array}$ & $\begin{array}{l}0.249^{* * *} \\
(0.0898)\end{array}$ \\
\hline Low Disagreement & & & $\begin{array}{c}-0.116 \\
(0.0812)\end{array}$ & $\begin{array}{c}-0.122 \\
(0.0915)\end{array}$ & & \\
\hline Constant & $\begin{array}{l}0.403^{* * *} \\
(0.0662)\end{array}$ & $\begin{array}{l}-0.658 \\
(0.475)\end{array}$ & $\begin{array}{l}0.403^{* * *} \\
(0.0663)\end{array}$ & $\begin{array}{l}-0.181 \\
(0.455)\end{array}$ & $\begin{array}{l}0.287^{* * *} \\
(0.0472)\end{array}$ & $\begin{array}{c}-1.019^{* * *} \\
(0.276)\end{array}$ \\
\hline Control Group & Baseline & Baseline & Baseline & Baseline & Low Dis & Low Dis \\
\hline Covariates & $\mathrm{N}$ & $\mathrm{Y}$ & $\mathrm{N}$ & $\mathrm{Y}$ & $\mathrm{N}$ & $\mathrm{Y}$ \\
\hline$N$ & 1846 & 1846 & 1458 & 1458 & 1332 & 1332 \\
\hline
\end{tabular}


Table 13: Comparison of Runoff Treatments vs. No Upset

\begin{tabular}{|c|c|c|c|c|c|c|}
\hline & $\begin{array}{c}(1) \\
\text { Vote B }\end{array}$ & $\begin{array}{c}(2) \\
\text { Vote B }\end{array}$ & $\begin{array}{c}(3) \\
\text { Vote B }\end{array}$ & $\begin{array}{c}(4) \\
\text { Vote B }\end{array}$ & $\begin{array}{c}(5) \\
\text { Vote B }\end{array}$ & $\begin{array}{c}6) \\
\text { Vote B }\end{array}$ \\
\hline Baseline & $\begin{array}{c}-0.258^{* *} \\
(0.129)\end{array}$ & $\begin{array}{c}-0.279^{* *} \\
(0.118)\end{array}$ & & & & \\
\hline Small Minority & & & $\begin{array}{l}-0.111 \\
(0.151)\end{array}$ & $\begin{array}{l}-0.107 \\
(0.127)\end{array}$ & & \\
\hline Low Disagreement & & & & & $\begin{array}{c}-0.375^{* * *} \\
(0.121)\end{array}$ & $\begin{array}{c}-0.392^{* * *} \\
(0.106)\end{array}$ \\
\hline Constant & $\begin{array}{c}0.662^{* * *} \\
(0.110)\end{array}$ & $\begin{array}{c}0.487 \\
(0.400)\end{array}$ & $\begin{array}{c}0.662^{* * *} \\
(0.111)\end{array}$ & $\begin{array}{c}-0.0948 \\
(0.464)\end{array}$ & $\begin{array}{c}0.662^{* * *} \\
(0.111)\end{array}$ & $\begin{array}{c}0.546 \\
(0.478)\end{array}$ \\
\hline Control Group & $\mathrm{R}_{-} \mathrm{NU}$ & $\mathrm{R}_{-} \mathrm{NU}$ & $\mathrm{R}_{-} \mathrm{NU}$ & $\mathrm{R}_{-} \mathrm{NU}$ & $\mathrm{R}_{-} \mathrm{NU}$ & $\mathrm{R}_{-} \mathrm{NU}$ \\
\hline Covariates & $\mathrm{N}$ & $\bar{Y}$ & $\bar{N}$ & $\bar{Y}$ & $\mathrm{~N}$ & $\bar{Y}$ \\
\hline$N$ & 1835 & 1835 & 1709 & 1709 & 1321 & 1321 \\
\hline
\end{tabular}

Table 14: Runoff Condition and Election Outcomes (Baseline and Low Disagreement)

\begin{tabular}{|c|c|c|c|c|c|c|}
\hline & $\begin{array}{c}(1) \\
\text { A Victory }\end{array}$ & $\begin{array}{c}(2) \\
\text { B Victory }\end{array}$ & $\begin{array}{c}(3) \\
\text { C Victory }\end{array}$ & $\begin{array}{c}(4) \\
\text { A Victory }\end{array}$ & $\begin{array}{c}(5) \\
\text { B Victory }\end{array}$ & $\begin{array}{c}(6) \\
\text { C Victory }\end{array}$ \\
\hline Baseline & $\begin{array}{c}0.0433 \\
(0.0334)\end{array}$ & $\begin{array}{c}0.0111^{* *} \\
(0.00532)\end{array}$ & $\begin{array}{l}-0.0544^{*} \\
(0.0328)\end{array}$ & & & \\
\hline Low Disagreement & & & & $\begin{array}{l}-0.0267 \\
(0.0306)\end{array}$ & . & $\begin{array}{c}0.0267 \\
(0.0306)\end{array}$ \\
\hline $\begin{array}{l}\text { Control Group } \\
N\end{array}$ & $\mathrm{P}_{660} \mathrm{~B}$ & $\mathrm{P}_{660} \mathrm{~B}$ & $\mathrm{P}_{66} \mathrm{~B}$ & $\mathrm{P}_{600} \mathrm{LD}$ & $\mathrm{P}_{600} \mathrm{LD}$ & $\mathrm{P}_{\overline{600}} \mathrm{LD}$ \\
\hline
\end{tabular}


Table 15: Election Outcomes in Small Minority and No Upset vs. Runoff Baseline

\begin{tabular}{|c|c|c|c|c|c|c|}
\hline & $\begin{array}{c}(1) \\
\text { A Victory }\end{array}$ & $\begin{array}{c}(2) \\
\text { B Victory }\end{array}$ & $\begin{array}{c}(3) \\
\text { C Victory }\end{array}$ & $\begin{array}{c}(4) \\
\text { A Victory }\end{array}$ & $\begin{array}{c}(5) \\
\text { B Victory }\end{array}$ & $\begin{array}{c}(6) \\
\text { C Victory }\end{array}$ \\
\hline Small Minority & $\begin{array}{c}0.0567 \\
(0.0424)\end{array}$ & $\begin{array}{c}0.0356 \\
(0.0245)\end{array}$ & $\begin{array}{c}-0.0922^{* * *} \\
(0.0287)\end{array}$ & & & \\
\hline No Upset & & & & $\begin{array}{l}-0.0533 \\
(0.0592)\end{array}$ & $\begin{array}{c}0.119^{* *} \\
(0.0530)\end{array}$ & $\begin{array}{l}-0.0656^{*} \\
(0.0346)\end{array}$ \\
\hline $\begin{array}{l}\text { Control Group } \\
N\end{array}$ & $\begin{array}{c}R_{-} B \\
660\end{array}$ & $\mathrm{R}_{660}^{\mathrm{B}}$ & $\mathrm{R}_{660} \mathrm{~B}$ & $\mathrm{R}_{660} \mathrm{~B}$ & $\mathrm{R}_{660} \mathrm{~B}$ & $\mathrm{R}_{660} \mathrm{~B}$ \\
\hline
\end{tabular}

Table 16: Runoff Condition and Election Outcomes (Small Minority and No Upset)

\begin{tabular}{|c|c|c|c|c|c|c|}
\hline & $\begin{array}{c}(1) \\
\text { A Victory }\end{array}$ & $\begin{array}{c}(2) \\
\text { B Victory }\end{array}$ & $\begin{array}{c}(3) \\
\text { C Victory }\end{array}$ & $\begin{array}{c}(4) \\
\text { A Victory }\end{array}$ & $\begin{array}{c}(5) \\
\text { B Victory }\end{array}$ & $\begin{array}{c}(6) \\
\text { C Victory }\end{array}$ \\
\hline Small Minority & $\begin{array}{l}-0.00667 \\
(0.0436)\end{array}$ & $\begin{array}{l}0.0433^{*} \\
(0.0243)\end{array}$ & $\begin{array}{l}-0.0367 \\
(0.0300)\end{array}$ & & & \\
\hline No Upset & & & & $\begin{array}{r}-0.01000 \\
(0.0623)\end{array}$ & $\begin{array}{l}0.130^{* *} \\
(0.0530)\end{array}$ & $\begin{array}{c}-0.120^{* * *} \\
(0.0398)\end{array}$ \\
\hline $\begin{array}{l}\text { Control Group } \\
N\end{array}$ & $\mathrm{P}_{6} \mathrm{SM}_{600}$ & $\mathrm{P}_{6} \mathrm{SM}$ & $\mathrm{P}_{6}{ }_{600} \mathrm{SM}$ & $\begin{array}{c}\mathrm{P}_{6} \mathrm{~B} \\
600\end{array}$ & $\begin{array}{c}\mathrm{P}_{6} \mathrm{~B} \\
600\end{array}$ & $\begin{array}{c}\mathrm{P}_{6} \mathrm{~B} \\
600\end{array}$ \\
\hline
\end{tabular}




\section{A5. Indifference Threshold with Risk Aversion}

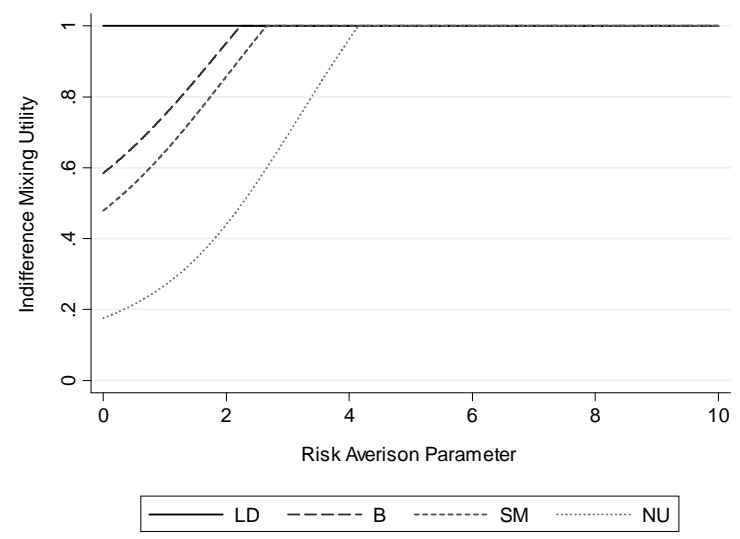

Figure 12: Probability of sincere voting of other $t_{B}$-voters that makes a $t_{B}$-voters indifferent between voting sincerely and voting strategically, as a function of the CRRA risk aversion parameter.

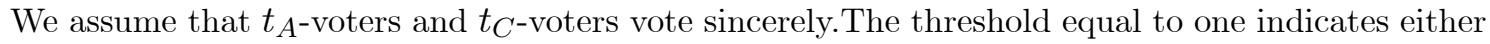
indifference when all $t_{B}$-voters vote sincerely or that sincere voting is never a best response. 
A6. Utilities of $t_{B}$ voters

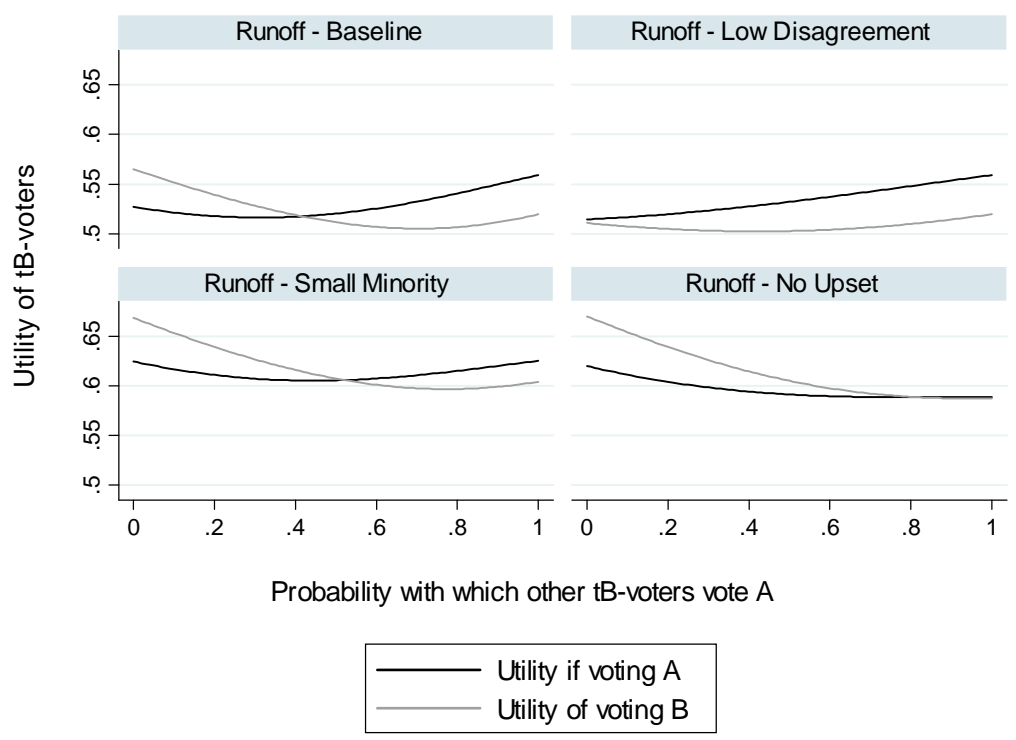

Figure 13: Utilities of tB-voters depending on the action they take and the mixing probabilities of the other tB-voters. In order to compute these utilities, we assume that tAand $\mathrm{tC}$ voters vote their preferred option with probability one. 


\section{A7. Figure Additional Treatments}

(i) Always Duvergerian

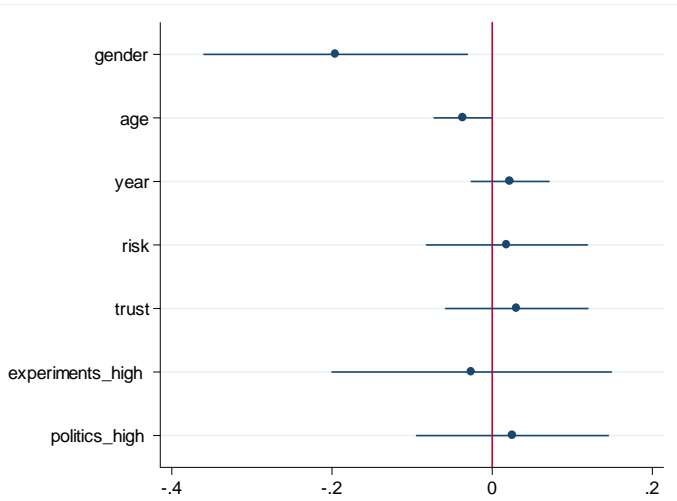

(ii) Always Sincere

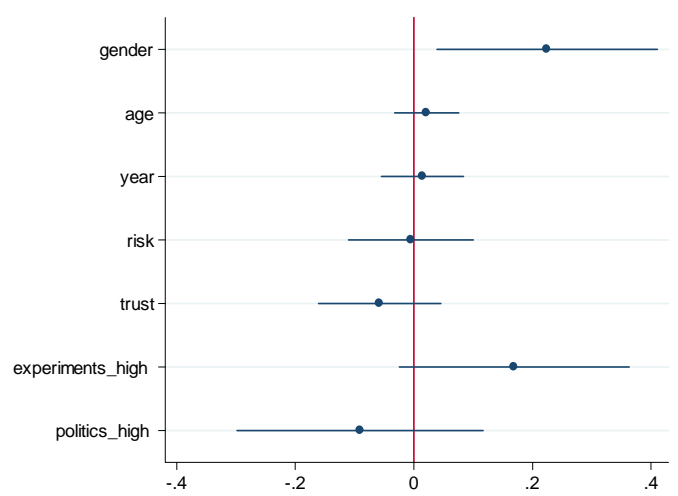

Figure 14: Individual characteristics and "always Duverger" and "always sincere" behavior. 


\section{A8. Instructions}

These are the instructions for the Baseline treatments. Instructions for the other treatments were exactly the same except for parameters in blue, which determine probabilities of types and winners in the second round.

General Indications. Hello and welcome to the experiment. We appreciate your time and disposition for participating in this academic exercise. We would like to remind you that your answers and choices are anonymous, confidential, and that they will be used strictly for academic purposes. Also, remember that in addition to the show-up fee, at the end of the experiment you will be paid according to your performance in the experiment. Throughout the exercise we will use dollars to express the benefits you obtain from your decisions.

Please feel free to ask any questions about the experiment's instructions before we start. Remember that during the experiment you cannot talk or communicate with any other subject in this room, unless otherwise stated. In your desk you will find a consent form and a pen. Please read and sign the consent form before we begin. You will also find a piece of paper, which can be used during the experiment in case you need to do any calculations. Any other things, such as cell phones or other devices, cannot be used during the experiment.

Experiment's Instructions. The experiment is composed of 60 periods. The rules are the same for all periods. At the beginning of the experiment, you will be randomly assigned to a group of 12 (including yourself). However, you will not know the identity of them, and they will not know your identity. You will belong to the same group throughout the whole experiment.

Your earnings will depend partly on your decisions, partly on the decisions of the other participants in your group and partly on chance. After each period, you will earn certain amount of dollars. At the end of the experiment, the computer will randomly select three periods, and you will earn the sum of dollars you get in these three periods. Each of the 60 periods has the same chance of being selected. Additionally, you will get a show-up fee of $\$ 7$.

Your Role. At the beginning of every period, the first thing the computer will do is to randomly assign you a role out of three possibilities: you can be a green, a purple, or a yellow voter. Allocation of roles is as follows: before each period starts, you will see the urn depicted in the next figure.

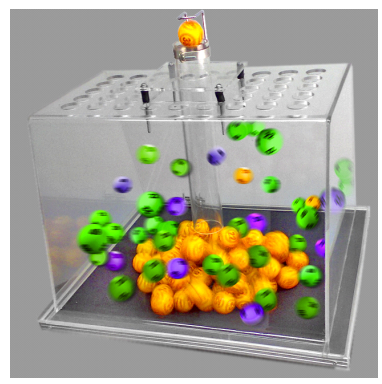

This urn contains 100 balls: 34 are green, 22 are purple, and 44 are yellow. After you click OK, one ball will be selected at random by the computer. If it is a green ball, you will be a green voter; if it is purple you will be a purple voter; and if it is yellow you will be a yellow voter. Therefore, you have a 34 percent chance of being a green voter; 22 percent chance of being a purple voter; and 44 percent chance of being a yellow voter.

Your decision. After your role is assigned, an election is held between three candidates: the 
green, the purple, and the yellow candidates. You have to decide for which candidate you cast your vote. That is, you have to decide whether to vote for green, vote for purple, or vote for yellow.

Winning Candidate [If Runoff]. When all participants have taken their decision, the votes of all participants will be added up. The winning candidate will depend on the final amount of votes that each color receives.

- If the candidate who obtains the largest number of votes in the first round receives 7 votes or more, this candidate is declared the winner.

- If the candidate with the largest number of votes in the first round obtains less than 7 votes, then the two top vote receivers face each other in a runoff election, which will be called the second round. If two candidates are tied in the second place, the tie is broken by alphabetical order. Similarly, if there is a triple tie, green and purple go to the second round.

The winner of the second round is randomly chosen by the computer by drawing a ball from an urn that contains 100 balls. The winning candidate is the color of the random ball.

- If the green and the purple candidates face in the second round, the urn contains $\mathbf{7 8}$ green balls and 22 purple balls.

- If the green and the yellow candidates face in the second round, the urn contains $\mathbf{7 6}$ green balls and 24 yellow balls.

- If the purple and the yellow candidates face in the second round, the urn contains $\mathbf{7 6}$ purple balls and 24 yellow balls.

Winning Candidate [If Plurality]. When all participants have taken their decision, the votes of all participants will be added up. The candidate who obtains the largest number of votes is declared the winner. If there is a tie for the first place, the tie is broken by alphabetical order.

Your payoff. Your final payoff for each period depends on your role and on who wins the election in that period. The next table summarizes the payoff that you get depending on your role and on the winning candidate:

\section{Winning Candidate}

\begin{tabular}{ll|c|c|c|}
\multirow{2}{*}{} & \multicolumn{1}{c}{} & \multicolumn{1}{c}{ Green } & Purple & \multicolumn{1}{c}{ Yellow } \\
\cline { 3 - 5 } Your Role & Green & 11 & 8 & 1 \\
\cline { 3 - 5 } & Purple & 8 & 11 & 1 \\
\cline { 3 - 5 } & Yellow & 1 & 1 & 11 \\
\cline { 3 - 5 } & & & &
\end{tabular}

The top part of the table indicates the winner of the election and the left part of the table indicates your role.

- If you are a green voter and the winning candidate is the green one, your payoff is $\$ 11$.

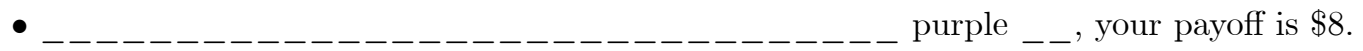

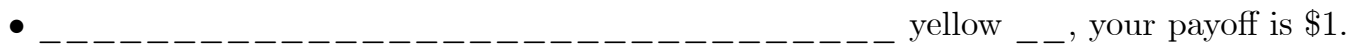

- If you are a purple voter and the winning candidate is the green one, your payoff is $\$ 8$.

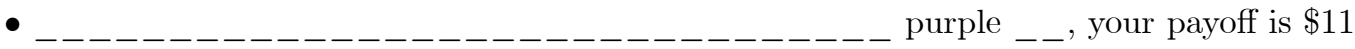

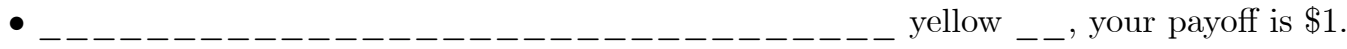

- If you are a yellow voter and the winning candidate is the green one, your payoff is $\$ 1$.

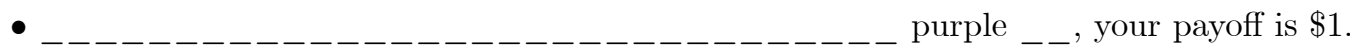

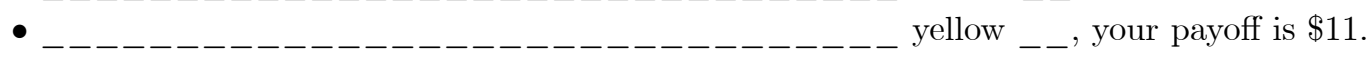

Information at the end of each Round 
Once you and all the other participants have made your choices, the winning candidate will be determined and the period will be over. At the end of each round, you will receive information about the vote shares of candidates on every previous period, whether a second round was necessary or not, and the winning candidate.

Control Questions. Before starting the experiment, you will have to answer some control questions in the computer terminal. Click Ok after you have answered all the questions of a page. Please feel free to ask any questions about the experiment's instructions. Once you and all the other participants have answered all the control questions, the experiment will start. 